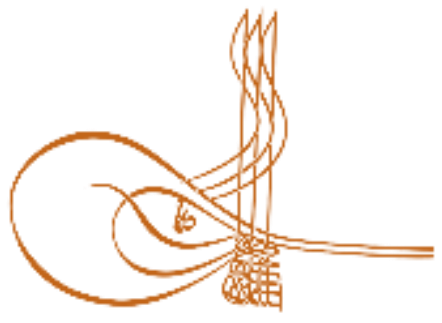

www.turkishstudies.net/social
Turkish Studies - Social Sciences

eISSN: $2667-5617$

Research Article / Araştırma Makalesi

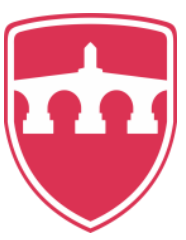

INTERNATIONAL

BALKAN

UNIVERSITY

Sponsored by IBU

\title{
Dijital Oyunlarda Nefret Söylemi ve Ayrımcı Dil: Agar.io Örneği
}

\author{
Hate Speech and Discriminatory Language In Digital Games: The Case of Agar.io
}

\author{
Hülya Öztekin* - Ahmet Öztekin**
}

\begin{abstract}
In this study, the forms of development and dissemination of hate speech and discriminatory language in digital online games have been discussed as an issue that we face in many aspects of daily life and that threatens the culture of social coexistence. The aim of the study is to identify forms of hate speech and discriminatory language created by users in digital online games, and to highlight the role of these games in spreading and normalizing hate speech and discriminatory language. Agar.io, one of the MMOG (massively multiplayer online games) games, was selected as the sample in the study. The Agar.io game was analyzed over an eight-week period in relation to hate speech and discriminatory language. Content analysis was used to analyze the data gathered through participatory evaluation and reached at the conclusion that online digital games have a significant influence in the creation and dissemination of hate speech and discriminatory language. It was determined that the game selected as a sample was not played by the players for entertainment and spending free time purposes only; it was determined that the players transformed the game into an environment where they created and spread hate speech and discriminatory language. As a result of the study, all forms of hate speech and discrimination were found in both avatar names and avatar images, including political / ideological, homophobic, xenophobic, racist and sexist forms. It has also been found that players use digital games online as a social media environment, aim to send personal messages for specific reasons, and digital games have developed into a new kind of social media environment and are often used for various purposes, such as propaganda and advertisement.
\end{abstract}

Structured Abstract: Hate speech and the use of discriminatory language, which is one of the world's major social issues, are becoming highly apparent in society. However, this exposure will not contribute to the creation or social abandonment of a collective consciousness that will alter the current situation, nor does it contribute to further normalization, banality, propagation and more social tolerance of hate speech and discriminatory language. Today, where technological advances are rapidly evolving and mobile devices are becoming an integral part of daily life, the content generated and distributed over the internet often negatively

\footnotetext{
${ }^{*}$ Dr. Öğr. Üyesi, Erciyes Üniversitesi, İletişim Fakültesi, Radyo, Televizyon ve Sinema Bölümü Asst. Prof. Dr., Erciyes University, Faculty of Communication, Radio, Television and Cinema Department ORCID 0000-0003-4599-9906

hoztekin@erciyes.edu.tr

*** Dr. Öğr. Üyesi, Erciyes Üniversitesi, İletişim Fakültesi (Radyo, Televizyon ve Sinema Bölümü) Asst. Prof. Dr., Erciyes University, Faculty of Communication (Radio, Television and Cinema Department) ORCID 0000-0001-7525-2788

aoztekin@outlook.com

Cite as/ Atıf: Öztekin H., Öztekin A. (2020). Dijital oyunlarda nefret söylemi ve ayrımcı dil: agar.io örneği, Turkish Studies - Social, 15(1), 533-558. https://dx.doi.org/10.29228/TurkishStudies.39019

Received/Geliş: 10 October/Ekim 2019

Accepted/Kabul: 25 February/Şubat 2020

Copyright $(\mathrm{C}$ INTAC LTD, Turkey
} 
supports this cycle. From video sharing sites to social media networks, from blog sites to digital games, environments where hate speech and racist language have been created and distributed in an uncontrolled manner.

Digital games, one of the common types of entertainment in modern life, are content where there is extensive use of hate speech and discriminatory language. Hate speech and discriminatory language in digital games are becoming normal and acceptable in relation to gaming and entertainment, making it easier to conceal. Therefore, digital games can be said to play a major role in the learning and normalization of hate and discrimination, particularly as digital games are considered to have an important place in the learning and socialization cycle of children and young people.

Looking at the academic literature on digital games, which has become the focus of academic circles in recent years, we can see that there is a wide range of current studies. The multidisciplinary nature of game research is also increasing diversity. Within this framework, a number of researchers from different disciplines, from economists to litterateurs, have studied the games (Salen ve Zimmerman, 2004, p. 72). These studies range from consumer behavior of players to gender representation in games, from digital game history to game narratives, from visual to character design in games, to social and psychological effects of digital games.

Games are also dealt with in studies of the social and psychological impact of digital games through harmful effects such as addiction (Uysal, 2017; Yalçın Irmak and Erdoğan, 2016), aggressive behavior and desensitization to violence (Adachi and Willoughby, 2011; Gentile et al ,2004; Greitemeyer, 2018), loss of academic performance (Anand, 2007; Wallenius et al, 2009), mental illness (Poppelaars et al, 2018; Valadez and Ferguson, 2012) and antisocial personality (Kowert el al, 2014). Furthermore, the discriminatory language and hate content used in digital games and the negative effects of such content can often be overlooked. However, the production and consumption of digital games often involve discriminatory language and hate content. While the elements used in the script and visual designs of the games reproduce sexist, homophobic, xenophobic, militaristic and racist dominant values, players are involved in this reproduction process by sharing in-game audio, visual and text content, user and avatar names of their choice, avatar images. In this study, the forms of production and distribution of hate speech and discriminatory language in online digital games were discussed as a problem that we face in many areas of everyday life and which undermines the culture of social coexistence. The aim of the study is to identify the forms of hate speech and discriminatory language produced by users in online digital games, and to draw attention to the role of these games in the spread and normalization of hate speech and discriminatory language.

Agar.io, one of the MMOG (massive online multiplayer) games, was selected as the sample in the study. Agar.io game was analyzed in eight-week duration from 20.05.2019 to 14.07.2019, with random entries made on three days on weekdays and at set time intervals, for a total of 15 minutes per day. A preliminary analysis was performed one week before the evaluation period to determine the time periods at which the number of players in the game is high, in order to determine the time zones where the number of players in the game is lowest. As a result of the preliminary investigation it was determined to investigate the time interval between 12:00-17:00 where the highest attendance was. The study investigated the names of avatars and avatar images used as unit of analysis by players. Content analysis was used to analyze the data. The study of Binark and Çomu (2012) was used to categorize these data and evaluated the categories "political hate speech, hate speech against foreigners and immigrants, hate speech against women, hate speech based on religious belief and sectarian, hate speech based on sexual identity, hate speech against the disabled and various diseases". In addition to these categories, the title 'hate speech based on racism and ethnic identity' was added in line with the need and a total of 7 categories were reviewed.

As a result of the examination, it was determined that $87 \%$ of the Agar.io players tried to emphasize the political, social, cultural, etc. values they felt belonging to and express themselves within this framework. Avatar names and images were often seen to be dominated by nationalist and male-dominated rhetoric. It was found that $58 \%$ of players who were concerned about posting via their avatars shared messages with hate speech and/or discriminatory language content. Consequently, the intention of messaging in these games, combined with in-game competitiveness, is embroiled in deliberate or accidental hate speech and/or discriminatory language, which is therefore subject to It was concluded that the discourses became a normal form of everyday language and became commonplace, normalized by constant consideration and social acceptance. It has been observed that players who choose similar political, religious, cultural, etc. names of 
avatars due to feelings like belonging to a community, being together, playing with each other in teams and finding other players with opposing views as the primary goal.

There have been some findings in the case of Agar.io, that MMOG-type games are increasingly turning into a new type of social media environment. Avatar names and images have been found to be used in parallel with social media usage purposes, similar to tweets, DMs, stories, situations and posts in various social media platforms. Games of this kind are played not only for gaming and entertainment purposes, but also for competing, taunting, propaganda, advertising, sending social messages, being with like-and fighting against opposing views, and are being used as new social media influenced by the national agenda.

The possibility of being able to participate fully anonymously in the game, and the feeling of being away from control and supervision, is thought to encourage players to produce and share messages that are illegal. In order to minimize such illegality and excesses, the requirement to verify / associate all online games with at least one e-mail account and at least one social media account or mobile phone number is presented as a solution for technical determination, which must be assessed both for providing players with self-control and for accessing players where necessary. The fact that hate speech and discriminatory language are a social problem alongside digital games also makes it necessary for solutions to be addressed from a wider perspective and for structural solutions to be introduced. For this reason, holistic measures should be taken to inform and raise awareness of hate speech and discriminatory language in the social life of individuals.

Keywords: Hate speech, discriminatory language, digital game, Agar.io.

Öz: Bu çalışmada, gündelik hayatın pek çok alanında karşılaştığımız ve toplumsal anlamda birlikte yaşama külttürünü zedeleyen bir sorun olarak nefret söylemi ve ayrımcı dilin online dijital oyunlardaki üretim ve dağıtım biçimleri ele alınmıştır. Çalışmanın amacı, online dijital oyunlarda kullanıcılar tarafından üretilen nefret söylemi ve ayrımcı dilin görülme biçimlerini ortaya koymak, bu oyunların nefret söylemi ve ayrımcı dilin yaygınlaşması ve normalleşmesindeki rolüne dikkat çekmektir. Çalışmada örneklem olarak MMOG (massively multiplayer online games) oyunlarından biri olan Agar.io seçilmiştir. Agar.io oyunu, sekiz haftalık süre boyunca nefret söylemi ve ayrımcı dil bağlamında incelenmiştir. Katılımlı gözlem tekniğiyle elde edilen veriler, içerik analizi yöntemiyle değerlendirilmiş; online dijital oyunların, nefret söylemi ve ayrımcı dilin üretimi ve yayımı noktasında önemli bir güce sahip olduğu bulgusuna ulaşılmıştır. Örneklem olarak seçilen oyunun, oyuncular tarafından sadece eğlence ve boş vakit geçirmek amacıyla oynanmadığı; oyuncuların, oyunu nefret söylemi ve ayrımcı dilin üretilip yayıldığı bir mecraya dönüştürdükleri tespit edilmiştir. Analiz sonucunda gerek avatar isimleri gerekse avatar görselleri düzleminde siyasal/ideolojik, homofobik, zenofobik, ırkçı ve cinsiyetçi olmak üzere nefret söylemi ve ayrımcıllğın bütün biçimleri görülmüştür. Ayrıca oyuncuların online dijital oyunları propaganda, reklam, kişisel iletişim gibi farklı amaçlarla sosyal medya şeklinde kullandıkları; dolayısıyla dijital oyunların yeni bir tür sosyal medya ortamına doğru evrildiği tespit edilmiştir.

Anahtar Kelimeler: Nefret söylemi, ayırımcı dil, dijital oyun, Agar.io.

\section{Giriş}

Modern dünyanın önemli toplumsal sorunlarının başında yer alan nefret söylemi ve ayrımcı dil kullanımı, her geçen gün artarak toplum içerisinde daha fazla görünür hale gelmektedir. Fakat bu görünürlük, mevcut durumu değiştirecek ortak bir bilincin oluşmasını ya da toplumsal olarak terk edilmesini sağlamadığı gibi nefret söylemi ve ayrımcı dilin daha da normalleşmesine, sıradanlaşmasına, yaygınlaşmasına ve dahası toplumsal olarak kabul görmesine neden olmaktadır. Bu bağlamda nefret söylemi ve ayrımcı dil sokakta, okulda, internette, medyada kısacası her yerde gündelik yaşamın doğal bir parçası haline gelmekte, bireysel ve toplumsal anlamda çevremizi sarmaktadır.

Teknolojik gelişmelerin büyük bir hızla ciddi mesafeler kat etmesi, özellikle internetin ve internet erişimli mobil cihazların gündelik yaşamın ayrılmaz bir parçası haline gelmesi, iletişim teknolojilerinin kullanıcılarını zaman ve mekândan bağımsız bir şekilde kuşatmasını da beraberinde getirmektedir. İnternet üzerinden gerçekleşen sanallaşma sınırlarının her geçen gün daha da artması, 
nefret söylemi ve ayrımcı dil kullanımının bu mecranın farklı içeriklerine de sıçramasına neden olmaktadır. Bu durum, video izleme sitelerinden sosyal medya ortamlarına, blog sitelerinden dijital oyunlara kadar farklı içeriklerin, bu söylemi online olarak üreten, yayan bir ortama dönüşmesini de beraberinde getirmektedir. Bu bağlamda toplumsal yaşamı derinden etkilemesi sebebiyle internet üzerinden erişilebilen tüm içeriklerin, detaylı olarak incelenmesi büyük önem arz etmektedir.

Turkle (1995), doğmakta olan bir simülasyon kültürünü sanal dünya üzerinden tartıştı̆̆ı 'Ekrandaki Yaşam: İnternet Çağında Kimlik' adlı kitabında, interneti hem yeni zihin modelleri hem de fikirlerimizi ve fantezilerimizi yansitabileceğimiz yeni bir ortam olarak sunmaktadır. Bu çerçevede interneti, postmodern yaşamı karakterize eden benliğin yapıları ve yeniden yapılanmaları ile ilgili deneme yapmak için önemli bir sosyal laboratuvar olarak görmektedir. Turkle'ın bu yaklaşımı, gerçek sosyal dünyadaki kahramanların, sanal dünya üzerindeki varoluşlarının ve davranışlarının incelenmesini gerekli kılmaktadır. İnternet için yapılan bu saptamayı, geniş anlamıyla online dünyanın tüm bileşenlerine uyarlamak mümkündür. Bu çalışmayla, online dijital oyunlardaki oyuncu kimliklerinin iletişimsel eylemleri, bahsi geçen sosyal laboratuvarda inceleme konusu olarak ele alınmış; nefret söylemi ve ayrımcı dil bağlamında değerlendirilmiştir. Çalışmanın amacı, online dijital oyunlarda kullanıcılar tarafindan üretilen nefret söylemi ve ayrımcı dilin görülme biçimlerini ortaya koymak, bu oyunların nefret söylemi ve ayrımcı dilin yaygınlaşması ve normalleşmesindeki rolüne dikkat çekmektir. Çalışmada örneklem olarak MMOG (massively multiplayer online games) oyunlarından biri olan Agar.io seçilmiştir. Araştırma verileri 20.05.201914.07.2019 tarihleri arasındaki sekiz haftalık sürede yapılan katılımlı gözlem tekniğiyle elde edilmiştir. Çalışmada analiz birimi olarak oyuncuların kullandığ 1 avatar isimleri ve avatar görselleri incelenmiş; bunların analizinde içerik analizi yöntemi kullanılmıştır.

\section{Yeni Medya Biçimi Olarak Dijital Oyun}

Oyunlar, genellikle eğlence amaçlı yapılan aktiviteler olarak bilinmektedir. Özellikle çocukluk döneminin vazgeçilmezleri arasında yer alan oyunların doğası zamanla değişse de bazen eğlenmek bazen de boş vakitleri değerlendirmek amacıyla her dönem gündelik hayatın bir parçası olmuşlardır. Doğada bulunan malzemelerin işlenerek, belirli amaçlar ve kurallar çerçevesinde kullanılır hale getirilmesiyle ortaya çıkan ilk oyunlarla, eğlencenin yanı sıra hayatta kalma pratiklerinin çocuklara kazandırılması da amaçlanmıştır. İnsanın doğuştan homo ludens, yani 'oyun oynayan insan' olduğunu ifade eden Huizinga'ya göre (2003, s. 28) oyun, olağan hayatın dışında yer aldığı hissedilen, özgür ve 'kurmaca' ama yine de oyuncuyu tamamen içine çekme yeteneğine sahip; her tür maddi çıkar ve yarardan arınmış bir eylemdir. Bu eylem bilhassa sınırlandırılmış bir zaman ve mekânda gerçekleşmekte, belirli kurallara uygun olarak, düzen içinde cereyan etmekte ve kendilerini gönüllü olarak bir esrar havasıyla çevreleyen veya alışılmış dünyaya yabancı olduklarını kılık değiştirerek vurgulayan grup ilişkileri doğurmaktadır.

Oyunu kısaca, kurallarla belirlenmiş bir çerçevede, hedeflerine ulaşmak isteyen iki ya da daha fazla sayıdaki bağımsız karar vericiler arasındaki bir aktivite (Abt, 1987, s. 6-7) şeklinde tanımlamak mümkündür. Salen ve Zimmerman da (2004, s. 83) benzer şekilde oyunu, oyuncuların ölçülebilir bir sonuçla tamamlanan, kurallarla sınırlı, yapay çatışmalara girdikleri bir sistem olarak değerlendirmektedir.

Teknolojinin hızlı gelişimi, geleneksel oyunları da derinden etkilemiştir. Günümüzde oyun dendiğinde akla ilk olarak dijital oyunlar yani bilgisayar ve konsol oyunları gelmektedir. İlk dijital oyunlar arcade olarak bilinen (ilk atari örnekleri) ve basit görselleri olan, birkaç tuş ya da joystick yardımıyla oynanabilen basit oyunlarken, bugünkü dijital oyunlar konuları, görselleri ve stratejileri ile bambaşka bir boyuta taşınarak kompleks bir hal almışlardır. Dijital oyunlar, kişisel bilgisayarların artmasıyla popülerlik kazanmış ve yaygınlaşmıştır.

Dijital oyunları geleneksel oyunlardan farklı kılan, birer yazılım veya bir başka deyişle dijital medya ürünü olmalarıdır. Dijital oyunlar aynı anda bir oyun, interaktif birer yazılım, görsel işitsel 
temsil aracı, çeşitli derecelerde anlatı içeren kurmaca yapıt ve sosyal paylaşım/etkileşim ortamıdır (Sezen, 2011, s. 120).

Arcade, bilgisayar, konsol ve mobil oyunların farklı türlerini kapsayan dijital oyunlar teknik ve tarihsel açıdan bilgisayar teknolojilerine paralel olarak gelişmiştir. Dijital oyunların ilk prototipi 1952 yılında Cambridge Üniversitesi doktora öğrencisi Alexander Sandy Douglas tarafından geliştirilmiştir. EDSAC ${ }^{1}$ bilgisayar üzerinde oynanabilen, sıfır ve artılardan oluşan Tic-Tac-Toe oyununun bir versiyonu olarak geliştirilen $\mathrm{OXO}$ isimli bu oyun, dünyanın ilk video oyunudur. 6 yıl sonra yani 1958'de Brookhaven Ulusal Laboratuarı'nda fizikçi olarak görev yapan William Higinbotham tarafindan tenis oyununun basit bir simülasyonu olan Tennis for Two isimli oyun geliştirilmiştir. Literatürde genellikle ilk bilgisayar oyunu olarak geçen bu oyun, kısa sürede laboratuvara gelen ziyaretçilerin temel eğlencesi haline gelmiştir. 1962 yılında Massachusetts Teknoloji Enstitüsü’nde Steve Russell yönetiminde bir grup araștırmacı tarafından Spacewar isimli oyun yazılmıştır. PDP- $1^{2}$ isimli bilgisayarda oynanan ve iki oyuncunun rakibin gemisini vurmay1 amaçladığı oyun Amerika'daki bir dizi akademik kurum tarafından kopyalanmıș ya da eklemeler yapılarak değiștirilmiştir. Ancak dijital oyunların evriminde en büyük değişim 1967 yılında metin tabanlı macera oyunu Advent'in geliştirilmesiyle yaşanmıştır (Kirriemuir, 2006, s. 22). Aynı yıl Ralph Baer tarafindan televizyonlara bağlanarak oynanan ilk oyun konsolu Brown Box tasarlanmıştır. Fakat Brown Box'ın ticari bir ürün haline gelmesi 1970'lerde mümkün olmuştur. 1972 y1lında Atari şirketi kurulmuş, şirket aynı yıl masa tenisi uyarlaması olan Pong isimli oyunu geliştirmiş̧ir. Büyük başarı sağlayan Pong 1970'lerin en başarılı oyunlarından biri olmuş ve zamanla başka platformlara da aktarılmıştır. 1977'de Atari şirketi Atari 2600 isimli oyun konsolunu piyasaya sürmüştür. Atari 2600, 1970'lerin sonu ve 1980'lerin ilk yarısında en popüler oyun konsollarından biri haline gelmiştir. İlk MUD (multi user dungeons) oyunu 1978 y1lında Richard Bartle ve Roy Trubshaw tarafindan geliştirilmiştir. 1980 yılında Namco şirketi, ilk video oyunu çılgınlığı sayılabilecek ve günümüze dek popülerliğini sürdüren oyun Pac-Man'i piyasaya sürmüştür. Oyun oynamak için tasarlanmış bir PC konfigürasyonu olan Commodore 64, 1982 yılında geliştirilmiştir. Nintendo şirketi Super Mario Bros. oyununu 1985 yılında piyasaya sürmüş, Mario karakteri oyun dünyasında son derece popüler olmuştur. 1994'te Sony şirketi PlayStation oyun konsolunu Japonya'da satışa çıkarmıştır. Yaklaşık 125 milyon satan PlayStation dijital oyun tarihinin en başarılı oyun konsollarından biri haline gelmiştir. 2001 yılında ise Microsoft şirketi yine bir oyun konsolu olan Xbox'1, Nintendo şirketi ise GameCube'u piyasaya sürmüştür. 2004 yllında sosyal paylaşım sitesi Facebook kurulmuş, sonraki dönemlerde sosyal paylaşım üzerinden oynanan oyunlar geliştirilmeye başlamıştır. Dijital oyunların beden hareketleri ile kontrol edilmesine imkân tanıyan oyun konsolu Nintendo Wii ise 2006 y1lında satışa çıkarılmış, böylece dijital oyun oynama edimi farklı bir boyut kazanmıştır (Sezen ve Sezen, 2011, s. 259-283).

Genel olarak dijital oyunlar şeklinde ifade edilen bilgisayar tabanlı oyunlar, oynandığ 1 platforma ve oyunun özelliklerine göre farklı türlere ayrılmıştır. Bu çerçevede Salen ve Zimmerman (2004, s. 86) dijital ve elektronik oyunların çok sayıda farklı biçimlere büründüğünü ve birçok farklı platformunda göründügünü ifade etmektedir. Dijital oyunlarla ilgili sınıflandırmalara bakıldığında oyun türleri üzerine bir uzlaşmanın olmadığ hemen dikkatleri çekmektedir. Oyun üreticileri ve dağıtıcıları bile bu konuda farklı yaklaşımlar sergilemektedirler (Clarke ve diğerleri, 2015; Apperley, 2006). Akademide ise her araştırmacı çalışmasının bağlamına göre oyunları farklı türler içerisinde değerlendirebilmektedir. Söz konusu oyunları ticari özelliklerine, kullanılan teknolojiye, çevrimiçi ya da çevrimdışı olmasına, oynandığı platforma, tekil ya da çoğulluğuna, mobil olması ya da

\footnotetext{
${ }^{1}$ Electronic Delay Storage Automatic Calculator (EDSAC), Cambridge Üniversitesi'nde Maurice Vincent Wilkes ve ekibi tarafından 1951'de geliştirilmiştir ve dünyanın ilk bilgisayarlarından birisi sayılmaktadır.

${ }^{2}$ Programmed Data Processor-1 (PDP-1) Digital Equipment Corporation'ın PDP serisindeki ilk bilgisayardır ve 1959'da üretilmiştir.
} 
olmamasına, ücretli olup olmamasına, grafiklerine/görsellerine, hikâye anlatılarına, kurgularına göre gibi yüzlerce farklı kritere göre sınıflandırmak mümkündür.

Farklı yaklaşımlar olmakla birlikte başlıca oyun türlerini FPS (First Person Shooter Kahramanın Gözünden Atış), RPG (Role Playing Game- Rol Yapma Oyunu), MMOG (Massively Multiplayer Online Games - Devasa Çok Oyunculu Çevrimiçi Oyunlar), MMORPG (Massively Multiplayer Online Role Playing Game- Devasa Çok Oyunculu Çevrimiçi Rol Yapma Oyunu), RTS (Real Time Strategy- Gerçek Zamanlı Strateji), TBS (TurnBasedStrategy- Sura Tabanlı Strateji), MOBA (Multiplayer Online Battle Arena- Çok Oyunculu Çevrimiçi Savaş Alanı), Simulation (Simülasyon), Advanture (Macera) ve Strategy (Strateji) şeklinde sıralamak mümkündür (Clarke ve diğerleri, 2015; Apperley, 2006).

Günümüzde eğlence sektörünün önemli bir parçası olan dijital oyunları sadece bir boş zaman etkinliği ve eğlence aracı olarak değerlendirmek yanlış olacaktır. Dijital oyunlar ekonomik değeri olan endüstriyel bir ürün, kültürel değerlerin temsil edildiği bir kültür ürünü ve aynı zamanda anlamın üretildiği bir metin niteliği taşımaktadır. Dijital oyun bir meta, medya endüstrisi ve kültürel bir pratik olarak post-endüstriyel neo-liberal kültürel ürünlerin ideal bir örneğini temsil etmektedir (Kerr, 2006, s. 1). Gelirleri Hollywood endüstrisini gelirlerini aşan dijital oyun sektörü, yarattığı sanal kahramanlarla sinema ve televizyon endüstrilerine de entegre olmuştur. İzleyicinin edilgen olduğu sinema, televizyon gibi- formatların aksine, oyuncunun karakteri canlandırdığı 'o' mekânda ve uzamda yaşadığı dijital oyunlar, başka bir semantiği ifade etmektedir. Üretim koşulları da dikkate alındığında, milyarlarca liralık bir sermayeyi ilgilendiren, dinamik, teknoloji açısından mükemmel denilebilecek üretim olanaklarına sahip, sanat ve estetiğin tüm olanaklarından faydalanan bir alan haline gelmiştir (Bat1, 2011, s. 5-6).

\section{Ayrımcı Dil ve Nefret Söylemi}

Ayrımcı dil ve nefret söylemi, demokratik toplumun ve birlikte yaşama kültürünün oluşması ve devam ettirilmesinin önündeki en büyük engellerdendir. Ayrımcılık, bir gruba ya da bir grubun üyelerine karşı, önyargılardan beslenen olumsuz tutum ve davranışların tümü ile ilgili bir süreçtir. Önyargılar ve dolayısıyla ayrımcılık, bir gruba ya da grup üyelerine yönelik olumsuz düşüncelerin yanı sıra hoşlanmama, hor görme, kaçınma ve nefret etmeye kadar uzanan olumsuz duyguları içeren tutumlara yol açmaktadır (Göregenli, 2013a, s. 21). Bir gruba ya da grup üyelerine yönelik olumsuz duyguları söyleme döken ayrımcı dil kullanımı gündelik hayatta egemen grubun/grupların dışında kalanları ötekileştirmekte ve yalnızlaştırmaktadır.

Yine önyargılardan ve ayrımc1lıktan beslenen nefret söylemi ise bir kişiyi ya da grubu ırk1, etnik kökeni, cinsiyeti, cinsel eğilimleri, dini, mezhebi, siyasal tercihi, ideolojisi, sosyo-ekonomik durumu, fiziksel özellikleri, fiziksel engeli ya da hastalığı nedeniyle ayırt etme, dışlama, ötekileştirme, aşağılama, hedef gösterme, yıldırma, düşmanlaştırma gibi nefret biçimlerini ifade eden, yayan, teşvik eden, savunan dilsel pratiklerdir (Öztekin, 2015, s. 925). Nefret söylemi, toplumdaki güçsüz ve marjinal gruplara yönelik nefret ve şiddet iklimine katkıda bulunduğu için oldukça tehlikelidir (Gelber, 2002, s. 1).

İnsan, doğasında var olan niteliğinin bir uzantısı olarak gruplaşma ve kendini bir gruba ait hissetme eğilimi içindedir. Bu eğilimin altında ise toplumsal bir kazançtan öte, bireysel bir çıkar gözetimi yani olumlu bir öz değerlendirme ve benlik saygısını yüceltme gereksinimi yatmaktadır. $\mathrm{Bu}$ noktada karşımıza, kimlik duygusunun önemli bir boyutu olan 'sosyal kimlik' kavramı çıkmaktadır (Demirtaş-Madran, 2013, s. 74). Sosyal kimlik, bireyin benlik algısının, bir sosyal gruba ya da gruplara üyeliğine ilişkin bilgisinden ve bu üyeliğe yüklediği değerden ve duygusal anlamlılıktan kaynaklanan parçasıdır (Tajfel, 1982, s. 2). Kendisini sosyal kimlik yani grup üyeliği üzerinden tanımlayan birey, çoğunlukla diğer insanları da 'birey' olarak değil, bir toplumsal 'grubun üyesi' olarak algılamaktadır. Bireyler 'insanlar' olarak değil 'erkekler', 'Müslümanlar', 'yaşlılar', 'Ermeniler' diye adlandırılmaktadır (Demirtaş-Madran, 2013, s. 79). 
Gerek kendisini gerekse çevresindeki bireyleri sosyal kimlik ve grup üyeliği üzerinden tanımlayan birey, olumlu bir öz değerlendirme yapmak ve kendi benlik saygısını yüceltmek adına üye olduğu grubu/grupları diğer sosyal gruplarla karşılaştırmakta ve sıklıkla kendi grubunu diğerlerinden üstün görmektedir (Cortese, 2006, s. 5). Özellikle grupla özdeşleşmenin çok güçlü olduğu durumlarda birey, diğer gruplara karşı ayrımcı ve ötekileştirici bir tutum geliştirebilmektedir. Tabi ki bu durum bireyin bütün sosyal kimlikleri için geçerli değildir; fakat toplumda egemen olan gruplara aitlik durumlarında sıklıkla görülmektedir. Özellikle egemen ideoloji tarafından 'meşru' ve 'normal' kabul edilen ve farklı biçimlerde yeniden üretilen sosyal kimlikler, toplumsal ayrımcılığı ve ötekileştirmeyi besleyebilmektedir.

Egemen ideoloji etnik aidiyet, dini inanış, ideoloji, siyasal tercih, cinsel tercih gibi referanslar üzerinden ideal/normal vatandaş olmanın sınırlarını belirlerken, bunun dışındaki kimlikleri benimseyip kendisini ait hissettiği farklı kimlikler üzerinden ifade edenleri ise 'iç mihraklar', 'vatan hainleri' ve 'bölücüler' olarak tanımlanmakta; böylece ulusal bütünleştirici bu kimlik tanımı dışında kalarak 'öteki'leştirilen kişi veya gruplar ırkçı, şovenist, militarist, zenofobik ve homofobik söylemlere hedef olmaktadır (Aygül, 2010, s. 111). Toplumsal açıdan 'farklı' olana yönelik ayrımcı ve ötekileştirici söylemler kimi zaman örtük ve dolaylı kimi zaman da doğrudan ortaya çıkmaktadır. Ayrımcılığın doğrudan ifade biçimi olan nefret söylemi ise bu ayrımcı ve ötekileştirici söylemlerin en şiddetli formudur.

Van Dijk'a göre (2000, s. 36) söylem, ırkçılığın ve ayrımcılığın sosyal ve bilişsel boyutları arasındaki önemli bir ara yüzdür. Irkçılığın ve ayrımcılığın toplumsal bir pratiği olarak söylem, aynı zamanda insanların 1rkçı inançlarının da temel kaynağıdır. Irkçılığı ve ayrımcılığı büyük ölçüde metinlerden ve konuşmalardan öğreniriz. Ders kitapları, dini, edebi ve diğer metinler, günlük konuşmalar, politik söylemler, anaakım medya, vb. kanallarla dolaşıma giren ve her gün yeniden üretilen ırkçı ve ayrımcı söylemler yaygınlaşmakta ve normalleşmektedir. Bu açıdan nefret söyleminin kökleri günlük hayatın içindedir ve oradan beslenmektedir. Hull'un da dediği gibi (2003, s. 531) önyarg1lı bireylerin zihnindeki olumsuz nitelemelerin derin kökleri, dünyadaki köklü eşitsizlikle eşleşmektedir. Kelimeler, o dili besleyen eşitsiz toplumun genel bir hatırlatıcısı olarak hareket etmektedirler.

Weber'e göre (2009, s. 4-5) nefret söylemi, rrka dayalı nefret, dini temelli nefret, homofobi, milliyetçilik ve etnik kökenciliğin yansıttı ğı nefret gibi çok sayıda durumdan oluşmaktadır. Nefret söyleminin uluslararası düzeyde kabul edilen tanımı Avrupa Konseyi Bakanlar Komitesi'nin 1997 yılı 20 sayılı tavsiye kararında yer almaktadır. İlgili karara göre nefret söylemi, ırkçı nefreti, yabancı düşmanlığını, anti-semitizmi ya da saldırgan milliyetçilik, etnomerkezcilik, ayrımcılık, azınlıklara, göçmenlere ve göçmen kökenli kişilere karşı düşmanlık gibi hoşgörüsüzlüğe dayanan diğer nefret biçimlerini yayan, teşvik eden, destekleyen ya da haklı gösteren her türlü ifade biçimidir (Council of Europe Committee of Ministers Recommendation No. R [97] 20).

Binark ve Çomu (2012) nefret söylemini, yöneldiği kişi ve gruplar açısından altı ana başlık altında ele almışlardır:

- Siyasal Nefret Söylemi

- Kadınlara Yönelik Nefret Söylemi

- Yabancilara ve Göçmenlere Yönelik Nefret Söylemi

- Cinsel Kimlik Temelli Nefret Söylemi

- İnanç ve Mezhep Temelli Nefret Söylemi

- Engellilere ve Çeşitli Hastalıklara Yönelik Nefret Söylemi

Nefret söylemi ve nefret suçları -'nefret' sözcügünün bir duygu ifadesi olması nedeniyleçoğunlukla nefret söylemi ve nefret suçlarının yöneldiği kişi ya da gruplardan 'hoşlanmama', 'nefret 
etme' ve bu duyguların ifade edilmesi biçiminde anlaşılmaktadır. Oysa nefret suçları ve bu davranışsal edimlerin zihinsel, ideolojik arka planını oluşturan ayrımcı dil ve nefret söylemi, olumsuz duyguları içermekle birlikte esasen toplumu oluşturan gruplar arasındaki sistematik hiyerarşiye işaret eden bir dişlama, değersizleştirme ve düşmanlaştırma ideolojisidir (Göregenli, 2013b, s. 57). Ayrımcı dil ve nefret söylemiyle bir yandan kişinin belirli bir gruba aidiyeti yüzünden küçük düşürülmesi, aşağılanması ve hedef gösterilmesi söz konusuyken, diğer yandan bu söylemi üreten gruba güç ve önem atfedilmektedir. Zira bazı gruplar bu yolla, kendilerinin öz değerlerini artırma yanılsaması içinde 'diğer'lerini değersizleştirme ve insani değerlerden uzaklaştırarak itibarsızlaştırma sürecine dahil olmaktadırlar (İnceoğlu ve Çoban, 2014, s. 73). Bu anlamda ayrımc1 dil ve nefret söylemi sadece yöneldiği kişi ya da grubu tehdit etmekle kalmamakta, toplumsal grupları içine alan hiyerarşik tabakalaşmayı yeniden inşa etmektedir.

Ayrımcı dil ve nefret söyleminin en önemli sonuçlarından biri, mağdurlarını sessizleştirmesidir (Gelber, 2002, s. 83). Nefret söylemini gerçekleştirirken telaffuz edilen kelimeler, belirli gruplar hakkında çeşitli klişeler yaratarak onların ötekileşmesine sebep olabilir ve bu söylemin devam ettirilerek yeniden üretilmesi halinde çeşitli gruplar üzerindeki baskıyı artırabilir. Tüm bu faktörler hedefteki grupları sinikleştirir, pasifleştirir ve demokratik bir sisteme eşit bir şekilde katılma cesaretlerini veya motivasyonlarını kırar. Aynı zamanda nefret söylemi karşılıklı saygıyı zehirler, nefret söyleminin hedefindeki gruplar müzakere süreçlerine, demokratik yaşama katılımda yavaş yavaş geri çekilmeye başlar. Nefret söylemi, hedefindeki gruplara toplumun bir parçası olmadıklarını dikte eder, dolayısıyla bu grupların tartışma, müzakere etme sürecine katılmaları için şevkleri kırılmış olur. Hedefteki gruplar demokratik bir toplumda katkılarını sunamaz hale gelir ve tüm müzakereler, onların katkıları olmadan devam eder. Dolayısıyla nefret söylemi karşılıklı saygıyı, hoşgörü kültürünü zedeler ve çeşitli bakış açılarının adil bir şekilde değerlendirilmesini, mütalaa edilmesini engeller (Alğan ve Şensever, 2010, s. 16-17).

\section{Dijital Oyunlarda Ayrımcı Dil ve Nefret Söylemi}

Son y1llarda akademik çevrelerin odağ haline gelen dijital oyunlarla ilgili akademik literatüre bakıldığında mevcut çalışmaların geniş bir çeşitliliğe sahip olduğu görülmektedir. Oyun araştırmalarının çok disiplinli bir yapıda olması çeşitliliği de artırmaktadır. Bu çerçevede oyunlar, ekonomistlerden edebiyatçılara kadar farklı disiplinlerden pek çok araştırmacı tarafından incelenmiştir (Salen ve Zimmerman, 2004, s. 72). Bu çalışmalar, oyuncuların tüketim davranışlarından oyunlarda cinsiyet temsiline, dijital oyun tarihinden oyun anlatılarına, oyunlarda görsellikten karakter tasarımına, dijital oyunların sosyal ve psikolojik etkilerine kadar pek çok konuda çeşitlilik göstermektedir.

Dijital oyunların sosyal ve psikolojik etkilerine ilişkin çalışmalarda oyunlar genellikle bağımlılık ${ }^{3}$, şiddet eğilimi ve şiddete karşı duyarsızlaşma ${ }^{4}$, akademik performans düşüklüğ̈̆ ${ }^{5}$, ruhsal rahatsızlıklar $^{6}$, anti-sosyal kişilik ${ }^{7}$ gibi olumsuz etkiler üzerinden ele alınmaktadır. Ancak dijital oyunlarda kullanılan ayrımcı dil ve nefret içerikleri ile bu içeriklerin yaratabileceği olumsuz etkiler genellikle gözden kaçmaktadır ${ }^{8}$. Oysa dijital oyunların hem üretim hem de tüketim boyutunda ayrımcı dile ve nefret içeriklerine sıklıkla rastlanmaktadır. Oyunların senaryo ve görsel tasarımlarında kullanılan öğelerle cinsiyetçi, homofobik, zenofobik, militarist ve ırkçı egemen

\footnotetext{
${ }^{3}$ Örneğin bkz. Uysal (2017), Yalçın Irmak ve Erdoğan (2016).

4 Örneğin bkz. Adachi ve Willoughby (2011), Gentile ve diğerleri (2004), Greitemeyer (2018).

5 Örneğin bkz. Anand (2007), Wallenius ve diğerleri (2009).

${ }^{6}$ Örneğin bkz. Poppelaars ve diğerleri (2018), Valadez ve Ferguson (2012).

${ }^{7}$ Örneğin bkz. Kowert ve diğerleri (2014).

${ }^{8}$ Dijital oyunlarda nefret ve ayrımcılık konusunda yapılan çalışmalar çoğunlukla cinsiyetçilik ve kadın temsili üzerine yoğunlaşmıştır. Örneğin bkz. Bayraktutan-Sütcü (2010), Bryce, Rutter ve Sullivan (2006), Kan (2012), Mou ve Peng (2009), Terek Ünal (2011).
} 
değerler yeniden üretilirken, oyuncular da oyun içi sesli, görsel ve metin içerikli paylaşımlarla, seçtikleri kullanıcı ve avatar isimleriyle, avatar görselleriyle bu yeniden üretim sürecine dahil olmaktadırlar.

Her ne kadar oyuncu, oyun oynamanın bir gereği olarak gerçek dünyadaki kimliğinden başka bir kimlikle oyuna dâhil olsa da oyunda tercih edilen sanal kimlik ve bu sanal kimliğe ait eylem ve söylemler oyuncunun gerçek kimliğinden izler taşımaktadır. Özellikle oyuncuları oyunda temsil eden çevrimiçi avatarlar ${ }^{9}$ çevrimdışı benliğin bir yansıması olarak görülmekte ve bu çevrimiçi dünyada benliğin bir tezahürü olarak değerlendirilmektedirler. Birçok oyuncu kullandığı avatarla derin ilișkiler kurma eğilimindedir. Bu nedenle avatar, yalnızca çevrimiçi ortamda kendi fiziksel temsili değil, aynı zamanda kendi sosyal çevresi içindeki bir sosyal varlık ve bu sosyal konumu izleyen ilgili bir pozisyondur (Kalng, 2004, s. 390-391). Bu çerçevede avatar ve oyuncu ilişkisi büyük önem taşımaktadır. Her ne kadar konuya ilişkin farklı yaklaşımlar bulunsa da oyuncu ile avatarı arasındaki ilişki genellikle para-sosyal bir yapı olarak ele alınıp incelenmekte (Banks, 2015) ve oyuncu-avatar ilişkisi sosyalliğin sürekliliği boyunca var olan bir ilişki türü olarak kabul edilmektedir (Banks ve Bowman, 2016, s. 216). Binark ve Bayraktutan-Sütcü'ye göre (2008, s. 57) sanal oyun dünyasında yaratılan avatarların söylemsel pratikleri ve edimlerinde, kişinin egosunun ve alter-egosunun, aidiyet tasarımının izini sürmek mümkündür. Dijital oyun dünyasında ne kadar farklı bir kimlik kurgusu üzerine yatırım yapılırsa yapılsın, belli olaylar ve durumlar karşısında sanal uzama taşınan toplumsal ve kültürel bagaj açılmakta, verili ve doğal kabul edilen öğelerden yararlanılmaktadır. Sanal uzamda yaratılan ve dijital oyun dünyasında performe edilen kimlik, son kertede bireyin 'persona'sının bir uzantısıdır. Oyuncular gündelik yaşamda aile çevresinde, arkadaşlık ağlarında, okul ve iș yaşamında edindikleri özelliklerini ve kazanımlarını, bu oyunlarda kullanmakta bir başka deyişle çevrimdışı habituslarını çevrimiçinde yeniden konumlandırmaktadırlar (Binark ve Bayraktutan-Sütcü, 2009, s. 277). Bu açıdan oyuncunun oyun içinde ürettiği cinsiyetçi, homofobik, zenofobik, militarist ve 1rkçı söylemler gerçek hayattan beslenmekte ve sanal uzamda da yeniden dolaşıma sokulmaktadır.

Dijital oyunlarda ayrımcı dil ve nefret öğesi, oyun ve eğlenceyle kurduğu ilişki bağlamında daha normal ve kabul edilebilir hale gelmekte, kendisini daha kolay gizleyebilmektedir. Bu durum, mevcut sorunu daha da derinleştirmekte ve tehlikeli hale getirmektedir. Ayrıca özellikle çocukların ve gençlerin öğrenme ve sosyalizasyon sürecinde dijital oyunların önemli bir yere sahip olduğu düşünülürse nefretin ve ayrımcıllı̆̆ı öğrenilmesi ve normalleşmesinde dijital oyunların büyük rolü olduğu söylenebilir.

\section{Metodoloji}

Online dijital oyunlarda kullanıcılar tarafindan üretilen nefret söylemi ve ayrımcı dilin görülme biçimlerini ortaya koymayı amaçlayan bu çalışma, söz konusu oyunların nefret söylemi ve ayrımcı dilin yaygınlaşması ve normalleşmesindeki rolüne dikkat çekmeye çalışmaktadır. Oyuncular arasında gerçekleşen etkileşim ve örtük iletişim çerçevesinde, oyuncuların eylemlerinin ve avatar ${ }^{10}$

\footnotetext{
${ }^{9}$ Sanal dünyada internet kullanıcılarını temsil eden bazı araçlar bulunmaktadır. Bu araçlar kullanıldığı sanal ortama göre değişebilmekle birlikte bazen bir görsel bazen bir metin bazen de her ikisi birlikte olabilmektedir. Oyuncuların sanal dünyadaki yansımaları olarak değerlendirebileceğimiz bu temsillere kısaca avatar denilmektedir. Avatar kelimesi, Sanskritçe kökenli olup enkarnasyon ya da Tanrı'nın fiziksel olarak vücut bulmuş hali anlamında kullanılmaktadır (Morningstar ve Farmer, 1991, s. 274; Galanxhi ve Nah, 2007, s. 771; Klang, 2004, s. 390). Avatarlar büyük anlık mesajlaşma sistemleri, çevrimiçi forum sistemleri ve çok kullanıcılı rol yapma oyunları gibi her türlü dijital ortamda, çevrimiçi etkileşimler için kullanıcıları ve botları temsil etmek amacıyla kullanılan dijital kimliklerdir (Nowak ve Rauh, 2006, s. 153; Schroeder, 2002, s. 1-2). Siber dünyada başkalarıyla iletişim kurabilmek ve etkileşime geçebilmek için kullandığımız bir ara form, kimliğimizin somutlaşmış bir enkarnasyonu ve ontolojik bir temsilidirler. Avatarlar genellikle gerçekle hayallerin karıșımından oluşmaktadır (Meadows, 2008, s. 23). İnternet kullanıcıları avatarlar sayesinde, sanal ortamda gerçek zamanlı olarak bedenlenerek grafiksel bir görüntüye kavuşmaktadırlar (Nowak, 2004).

${ }^{10}$ Oyuncuları temsil eden tüm görseller/skinler/tasarımlar vb. semboller, makale içerisinde 'avatar' olarak ifade edilecektir.
} 
seçimlerinin, diğer oyunculara iletmek istedikleri bir mesaj olduğu ve bu mesajın önemli bölümünün nefret söylemi ve/veya ayrımcı bir dille gerçekleştiği hipotezinden hareket edilmektedir. Çalışmada bahsedilen etkileşimin odak noktasını oyunlardaki sanal dünyanın, eylemleri ölçülebilir ve gözlemlenebilir bir parçası olan avatarlar oluşturmaktadır.

Nefret söylemi ve ayrımcı dilin sıradan günlük aktivitelerde bile kasıtlı ya da kasıtsız bir biçimde nasıl ortaya çıktığının tespit edilmesi, elde edilen veriler ışı̆̆ında nefret söylemi ve ayrımcı dil kullanımının engellenmesi için gerekli önlemlerin alınmasında bir yol gösterici olması, toplumsal bilinçlendirme ve bilgilendirmeyle farkındalık yaratılması ve akademik alandaki bilgi birikimine katkıda bulunması açısından önemli bir yere sahip olan bu çalışma, Türkiye'de online oyunlardaki nefret söylemi ve ayrımcı dili inceleyen az sayıdaki çalışmalar arasında yer almaktadır.

Çalışmanın evrenini MMOG (massively multiplayer online games) kategorisindeki oyunlar oluşturmaktadır. Örneklem olarak MMOG oyunlarından Agar.io seçilmiştir. 19 yaşındaki Brezilyalı bir öğrenci olan Matheus Valadares tarafindan geliştirilen Agar.io, 28 Nisan 2015 tarihinde piyasaya sürülmüştür. http://www.agar.ioadresinden ulaşılabilen oyun, ilk çıkışıyla birlikte oyun severlerin ilgi odağı olmuştur. Oyunun çıkmasından iki hafta gibi kısa bir süre sonra oyuncu sayısı 1 milyonu aşmış ("Efsane Oyunun", 2015), piyasaya sürüldükten sadece saatler sonra oyun AppStore listelerinde zirveye yükselmiştir (Christiansen, 2015). Agar.io'nun yayımlanmasından kısa bir süre sonra 40 milyondan fazla takipçisi bulunan popüler bir YouTube hesabı olan PewDiePie, Agar.io ile ilgili bazı komik videolar yayınlayarak oyunun bir viral olmasını sağlamıştır. Bu hızlı başarı, yılda yaklaşık 100 oyun üreten ve 200 milyon aktif kullanıcıya sahip MiniClip (Takahashi, 2017) adlı şirketin dikkatini çekmiş ve oyunun hakları şirket tarafından satın alınmıştır.

Agar.io, basit mantığına ve temel seviyedeki grafiklerine bakıldığında ilk başta dikkate değer gibi görünmemektedir. Ancak oyun dünya çapında onlarca farklı server (sunucu) üzerinde oynanarak web tabanlı oyunlar için yeni bir trend başlatmıştır. Agar.io'nun bu başarısının ardından web tabanlı MMOG tarzı bir diğer oyun olan Slitter.io Mart 2016'da piyasaya çıkmıştır. Böylece Agar.io bir türe adını vererek '.io' tarzı oyunlar şeklinde yeni bir kategori ortaya çıkartmıştır. Bu oyunları Brutes.io, Squadd.io, Vertix.io, Wormate.io, Diep.io, Mope.io, GunBox.io, Splix.io, Blash.io, Deeeep.io gibi yüzlerce benzer ve klon oyunlar takip etmiştir. Agar.io'nun öncülüğünü yaptığı '.io' tarzı oyunların aylık toplam ziyaretçisi 192 milyon aktif kullanıcıyı geçmiştir (Takahashi, 2017).

MiniClip yapımcısı Jamie Cason, 7 Şubat 2017'de Berlin'deki 'Casual Connect Europe' konuşmasında oyunun özellikle Brezilya, Rusya ve Türkiye gibi ülkelerde büyük bir pazar payı elde ettiğini belirmiştir (Takahashi, 2017). Agar.io o kadar popüler bir hale gelmiştir ki farklı dillerdeki oyun videoları YouTube da yüz milyonlarca kez görüntülenmiştir. Bloglarda hakkında yüzlerce yazı yazılmış, oyun ve teknoloji sitelerinde sürekli bahsi geçen bir oyun haline gelmiştir. Daha ilk yılında en popüler oyunlar arasına girmesi bile tek başına bir başarı olarak gösterilmektedir. Bu ilgi üzerine MiniClip şirketi Agar.io'nun IOS ve Android için mobil sürümünü 24 Temmuz 2015'te piyasaya sürmüştür. Oyun, Alexa.com'un en çok ziyaret edilen 1000 web sitesi listesinde yer almış ve mobil sürümleri ilk haftalarında on milyondan fazla indirilmiştir. Bu çerçevede MiniClip mobil başkanı Sergio Varanda, Agar.io'nun çevrim içi (web) olarak ciddi bir başarı elde ettiğini ABD, İngiltere ve diğer 32 ülkede de daha sadece bir oyun değil bir numaralı uygulama haline geldiğini belirtmiştir (Gordon, 2015). Netflix TV dizisi House of Cards'1n 48'inci bölümünde oyunun kısa bir tanıtımı yapılmıştır. Oyun, dizide ABD başkanını canlandıran karakter tarafından oynanmış ve içerik açısından siyasete benzetilerek oyunun mantığı ABD başkanlık yarışı ve seçim kampanyasıyla ilişkilendirilmiştir (Wikipedia). Bir milyonun üzerinde takipçi sayısına sahip video oyunları üzerine haber ve değerlendirmelerin yer aldığı bir site olan kotaku.com'da Nathan Grayson tarafindan yayımlanan "Siyasal Savaş Alanına Dönüşen Bir Oyun” başlıklı yazıda, Agar.io'nun çok fazla siyasal ve sosyal mesaj içeren bir oyun olduğu ve özellikle de Türkiye'den çok fazla sayıda mesaj verme çabasında olan oyuncuların yer aldığına değinilmiştir (Grayson, 2015). 
Agar.io üyeliksiz, kayıt ya da hesap oluşturma zorunluluğu bulunmayan, tamamen ücretsiz, her yerden ulaşılabilen, bilgisayara kurulum gerektirmeyen, herhangi bir özel donanım gereksinimi bulunmayan, ad, soyad, fotoğraf ya da mail gibi hiçbir kişisel bilgi talep etmeyen, dolayısıyla tamamen anonim olarak katılabileceğiniz, internet bağlantısı olan tüm cihazlarla uyumlu, iki boyutlu, sadelik ve basitlik üzerine kurulu, sadece fare ve iki klavye tuşu ile ('w', space) oynanabilen bir oyundur.

Oyuncular kullanıcı olarak, hiçbir özelleştirme yapmaksızın oyuna dahil olabildikleri gibi, avatar adı ve avatar görsellerinde özelleştirmeler de yapabilmektedir. Oyundaki tek amaç, oyuncunun kontrol ettiği hücrenin diğer hücreleri ya da peletleri (yemleri) yiyerek oyun sahasındaki en büyük hücre olmaktır. Bu amaç doğrultusunda oyuncular kendi aralarında takımlar oluşturabilmekte ya da iş birlikleri yapabilmektedirler. Oyun, adını bakterilerin kültürlenmesi için kullan agar plakasından almaktadır. Oyuna, petri kabı olarak düşünülen bir harita üzerinde küçük tek hücreli bir canlı olarak başlanır ve oyun alanı içerisinde 4 yönlü hareket edilerek yem ya da diğer hücrelerle beslenmek suretiyle en büyük tek hücreli canlı olmaya çalışılır. Her oyuncu tek bir hücre olarak başlar ve doğrudan ya da bölünerek diğer hücreleri yer. Dikkat edilmesi gerekenler sadece hücreleri parçalayan virüsler ve diğer büyük hücreli rakiplerdir. Oyunun oynadığı sunucuya göre değişmekle birlikte dünyanın her yerinden oyuncularla birlikte oynamak mümkündür. Oyunun sağ üst köşesinde yer alan LeaderBoard'da en büyük 10 oyuncunun avatar adı yer alır. Sağ alt köşesinde ise oyun alanının küçük bir haritası sol alt köşede ise oyuncunun skoru bulunmaktadır.

Agari.io, kurmaca bir hikayesinin olmayışı, bir senaryo üzerinden ilerlememesi, oyunculara verilmiş görevlerin bulunmayışı, oyuna katılım için hiçbir bilginin zorunlu olarak talep edilmeyişi, dolayısıyla oyuncuların her anlamda serbest ve özgür bırakılmış bir ortamda kimlikleri gizli, anonim olarak oyun oynayabilmeleri dolayısıyla denetimden/kontrolden/eleştiriden uzak olarak kendini rahatça/korkusuzca ifade edebilmeleri sebebiyle tercih edilmiştir. Bu bağlamda oyuncuların hiçbir kalıba girmemesi, önceden belirlenmiş herhangi bir davranışı ya da eylemi sergilemek zorunda kalmaması, oyuncunun yerine getirmesi gereken özel görevlerin bulunmayışı, anonim olarak oyuna katılmak suretiyle gerçek kimliklerini gizleyebilmeleri, avatar görseli ve avatar ad $1^{11}$ da dahil olmak üzere oyuncunun tercihleri doğrultusunda kendini ifade edebilmesi açısından maksimum özgürlüğe sahip oluşu, oyuncuların kendilerini ve düşüncelerini rahatlıkla ifade edebilmesi açısından önemlidir. Oyuncular kendilerini temsil edecek avatarlarını hazır bulunan görsellerden seçebildikleri gibi kendileri de yeni görseller/skinler üreterek ${ }^{12}$ de kullanabilmektedirler. $\mathrm{Bu}$ anlamda oyuncunun kendini ifade ediş biçimi için hiçbir sınırlama bulunmamaktadır. Dolayısıyla oyuncular diledikleri sembol, kelime ya da görselleri diledikleri şekilde oluşturarak kendilerini rahatça ifade edebilmektedirler.

Bilindiği üzere çevrimiçi oyunlarda iletişim biçimleri farklılıklar göstermektedir. Çoğu online oyun, metinsel sohbeti desteklerken bazıları farklı iletişimsel hareketlere imkân tanımakta bazıları da özel ve hedef/amaç odaklı etkileşim biçimleri üzerine yoğunlaşmaktadırlar (Manninen, 2003). Ancak örneklem olarak seçilen Agar.io oyununun oyun içi sohbeti desteklememesi nedeniyle avatar adları ve görselleri, oyuncuların diğer oyuncularla iletişime geçebilmesi, mesaj verebilmesi ya da kendini ifade edebilmesi amacıyla iletmek istedikleri mesajlarını taşıyabilecek tek ortam olarak karşımıza çıkmaktadır. Dolayısıyla, oyuncuların mesajını iletebileceği yegâne iletişim aracının kullandığı avatar olması hem oyuncuların mesajını herkese açık bir şekilde yayımlayarak mesajların gözlemlenebilir olmasını hem de oyuncular arası tüm iletişim ve etkileşimin ölçümlenebilir olmasını sağlayarak elde edilecek verilerin güvenilirliğini artırması adına önemlidir.

\footnotetext{
11 Oyun, oyuncuların en fazla 15 karaktere kadar avatar adı belirleyebilmesine izin vermektedir. Ancak bazı oyuncular hazırladıkları metinleri görsele (skin/avatar) dönüştürmek suretiyle karakter sayısı engelini aşabilmektedirler.

${ }^{12}$ Oyuncuların kendi avatar tasarımlarını yapabilmelerine olanak tanıyan yüzlerce farklı site ve uygulama bulunmaktadır.
} 
Araştırma verileri, örneklem olarak seçilen Agar.io oyununa 20.05.2019 - 14.07.2019 tarihleri arasındaki sekiz haftalık sürede, hafta içi üçer gün ve belirlenen saat aralıklarında yapılan rastgele girişlerle, günlük toplam 15 dakikalık katılımlı gözlem tekniğiyle elde edilmiştir. Oyundaki oyuncu sayısının en yüksek olduğu zaman dilimlerinin tespit edilmesi amacıyla inceleme süresinden bir hafta önce, oyundaki oyuncu sayılarının yüksek olduğu saat aralıklarını tespite yönelik bir ön araştırma yapılmıştır. Yapılan ön araştırma sonucunda oyuna en yüksek katılımın olduğu 12:0017:00 saat aralığının incelenmesine karar verilmiştir. Tüm oyuncular için olduğu gibi bizim için de oyun alanının bir bilinmeyen oluşu, sadece avatarımızın bulunduğu bölgeyi görebilmemiz/gözlemleyebilmemiz, her şeyin anlık olarak değişmesi gibi sebepler, oyun alanımıza giren avatar örneklerinin tam sayısına ulaşmayı imkânsız hale getirmiştir. Bu nedenle, ön araştırmanın yapıldığı bir haftalık süre içerisinde gözlem alanımıza giren avatarların dakikalık ortalaması hesaplanarak toplam örneklem rakamına ulaşılmıştır. Oyun esnasında (katılımlı gözlem) hipotezler bağlamında tespit edilen avatarlar ekran görüntüsü (screenshot) olarak kaydedilmiş, gözlem sonrasında ise kaydedilen görüntülerdeki avatarlar sayılarak oranlar çıkarılmıştır. Ön inceleme esnasında dakikada 18 Türkçe avatarın oyun/gözlem alanımız içerisine girdiği tespit edilmiş ve hesaplamalar oyunda kalınan/gözlem yapılan dakika x dakikadaki avatar ortalamas1 şeklinde yapılmıştır. Kısaca günlük 15 dakikalık gözlem $\mathrm{x}$ dakikada 18 avatar = günlük gözlemlenen toplam avatar sayıs 270 şeklinde hesaplanmıştır. Buna göre, dakikada 18 avatar x günde 15 dakika gözlem $\mathrm{x}$ hafta içi üç gün $\mathrm{x}$ sekiz hafta = gözlemlenen toplam avatar sayısı formülasyonu sonucunda 6480 sayısına ulaşılmış; yapılan tüm değerlendirmeler gözlemlenen 6480 avatar üzerinden gerçekleştirilmiştir.

İncelemenin yapıldığı tarih aralığında Türkiye'nin gündemini işgal eden çeşitli konuların bulunması (yenilenen yerel seçimler, ekonomik sorunlar, S-400 füze savunma sistemi, F-35 uçakları, göçmenler, terör operasyonları, dış politika, değişen iç siyasal dinamikler vb.) oyuna yansıyan gündemin keşfi ve gündem doğrultusunda ortaya çıkan söylemlerin incelenmesi açısından büyük önem ve çeşitlilik arz etmektedir. Bahsi geçen ulusal gündeme dair konuların oyuncuları daha fazla etkileyeceği; siyasal, kültürel, etnik ve dini kimliklerini daha fazla görünür hale getirmelerine neden olacağı tahmin edilmektedir.

Oyunun farklı sunucular (server) üzerinden oynanabilmesi ve farklı oyun modlarına sahip olması nedeniyle çalışma, Türkiye sunucusu ve en çok katılımın gerçekleştirildiği FFA moduyla sınırlandırılmıştır. Oyunda sürekli oyuncu sirkülasyonun bulunuşu (her an oyuna dahil olan yeni oyuncular ve oyunu kaybederek oyundan çıkan oyuncular) ve oyun doğası gereği oyun alanının tamamının gözlemlenememesi sebebiyle oyundaki tüm oyuncuların analizinin yapılamaması da bir başka sınırlılık olarak kabul edilmiştir. İnceleme her ne kadar Türkiye sunucusu üzerinden yapılsa da farklı dillerde de (İngilizce, Almanca, Rusça, Arapça, Kürtçe) hazırlanmış avatar adlarına da rastlanmıştır. $\mathrm{Bu}$ noktada da bir başka sınırlandırma yapılarak sadece Türkçe avatar adları değerlendirmeye alınmıştır.

Çalışmada yapılan analizlerin tamamı, belirtilen tarih ve saat aralıklarında gerçekleştirilen, yapılandırılmamış katılımlı gözlem tekniğiyle elde edilen verilere dayanmaktadır. Gözlem esnasında oyuna katıldığımız avatarla hem oyunun bulunulan alanı hem de LeaderBoard da yer alan oyuncular takip edilerek veri toplanmıştır. Çalışmada analiz birimi olarak oyuncuların kullandığı avatar isimleri ve avatar görselleri incelenmiştir. Elde edilen veriler, içerik analizi yöntemi kullanılarak değerlendirilmiştir. Söz konusu verilerin kategorilere ayrılmasında Binark ve Çomu'nun (2012) çalışmasından yararlanılmış ve "siyasal nefret söylemi, yabancılara ve göçmenlere yönelik nefret söylemi, kadınlara yönelik nefret söylemi, inanç ve mezhep temelli nefret söylemi, cinsel kimlik temelli nefret söylemi, engellilere ve çeşitli hastalıklara yönelik nefret söylemi" kategorileri kullanılmıştır. Duyulan ihtiyaç doğrultusunda bu kategorilere ek olarak "1rkçılık ve etnik kimlik temelli nefret söylemi" başlığı da eklenmiş ve toplam 7 kategoride inceleme yapılımıştır. 
Nefret söylemi ve/veya ayrımcı dil kullanımının online dijital oyunlardaki görünümünü konu edinen bu çalışmanın hipotezleri şunlardır:

1) MMOG türü oyunlarda oyuncular siyasal, kültürel, etnik, dini, vb. bireysel mesajlar verme kaygısı taşımaktadırlar ve online oyunları mesaj verebilecekleri bir ortam olarak görmektedirler.

2) MMOG türü oyunlarda oyuncuların mesaj verme kaygısı genellikle nefret söylemine ya da ayrımcı dile kayan aşırılıklara neden olmaktadır.

3) MMOG türü oyunlarda oyuncular, avatar görseli ve avatar ad seçimleriyle herkese açık görsel/sözel nefret söylemi üretmektedirler.

4) MMOG türü oyunlarda nefret söyleminin farklı türlerine rastlanmaktadır.

5) Ülke gündemindeki konular, MMOG türü oyunlara da yansıyarak oyundaki mesaj içeriklerini etkilemektedir.

\section{Bulgular ve Analiz}

Katılımlı gözlem tekniğiyle elde edilen veriler 1şığında, örneklem olarak seçilen oyunda nefret söylemi ve/veya ayrımcı dilin hem görsel hem de metinsel öğelerde ayrı ayrı oluştuğu tespit edilmiştir. Bu nedenle analizler, avatar adları ve avatar görselleri üzerinden ayrı başlıklar altında yapılmıştır.

\subsection{Avatar Adları}

İncelenen zaman dilimi içerisinde tespit edilen oyuncuların (6480 avatar) \%2'si (130 avatar) avatar adı kullanmazken ${ }^{13}$ yalnızca \%11'inin (712 avatar) siyasal, kültürel, etnik, dini vb. mesaj taşımayan ifadelerden (Pırasa, Mehmet, Yeşil, Kuş, Biber, Alper, Külah, Pervane, Sakız, Bıngıldak, vb.) avatar adları seçtikleri görülmüştür. Oyuncuların \%87’lik (5638 avatar) kısmının ise avatar adlarında ya da avatar görsellerinde siyasal, kültürel, etnik, cinsel ve dini kimliklerine ilişkin mesaj içerikli öğeler tespit edilmiştir. ${ }^{14}$ Yine benzer şekilde "Dürüst oynayın", "Ortak aranıyor", "w=ortak", "Satmayan ortak", "Takıma gel", "Ortak olak", "Türk ortak", "Takım için w at" gibi avatar adlarına da rastlanmış olması, avatar adları ya da görsellerinin oyunda mesaj verebilmenin tek yolu olduğunun bir başka kanıtı olarak değerlendirilmiştir.

Avatar adlarıyla ya da görselleriyle mesaj verme kaygısı taşıan grubun \%42'sinin (2368 avatar) nefret söylemi ya da ayrımcı dil içermeyen avatar adları kullanmayı tercih ettikleri tespit edilirken, avatar adlarında ya da görsellerinde nefret söylemi ya da ayrımcı dil kullanan oyuncuların oranının ise \%58 (3270 avatar) olduğu görülmüştür. Söz konusu mesaj verme kaygısı oyun içindeki rekabetle birleşince, karşıt görüşteki oyuncular başta olmak üzere oyuncuların geneline yönelik nefret söyleminin ve/veya ayrımcı bir dilin ortaya çıktı̆̆ı gözlemlenmiştir.

Gözlemin gerçekleştirildiği süre içerisinde, oyundaki nefret söylemi ve/veya ayrımcı dil kullanan toplam 3270 oyuncunun/avatarın \%79'unun (2583 avatar) 1rkçılık/etnik köken temelli, \%10'nun (327 avatar) siyasal/ideolojik temelli, \%5'nin (163 avatar) yabancılara ve göçmenlere yönelik, \%4'ünün (131 avatar) kadınlara yönelik, \%1'inin (33 avatar) inanç/mezhep temelli ve $\% 1$ 'nin de (33 avatar) cinsel kimlik temelli (LGBTI) nefret söylemi ve/veya ayrımcı dil olmak üzere toplamda 6 kategoride nefret söylemi ve/veya ayrımcı dili kullandıkları tespit edilmiştir. Engelli ve çeşitli hastalıklara yönelik nefret söylemi ve/veya ayrımcı dil kullanımına ise hiç rastlanmamıştır. Mesaj içerikleri çerçevesinde karşıt görüşlerle yaşanan bir ayrışma kadar, aynı nedenlerle benzer

\footnotetext{
${ }^{13}$ Avatar adı oluşturmayan oyunculara sistem tarafından otomatik olarak "An unnamed cell” adı atanmaktadır.

${ }^{14}$ Oyun içerisindeki botlar hiçbir istatistiki bilgiye dahil edilmemiştir.
} 
görüşler arasında doğal bir birleşmenin yaşandığı oyunda, rekabetin de etkisiyle çok ağır içeriklere sahip (küfür, müstehcen görseller/kelimeler) avatar adları ve avatar görselleriyle karşılaşılmıştır. ${ }^{15}$

Grafik 1: Avatar Adlarının Nefret Söylemi ve/veya Ayrımcı Dil Kullanımı Açısından Dağılımı

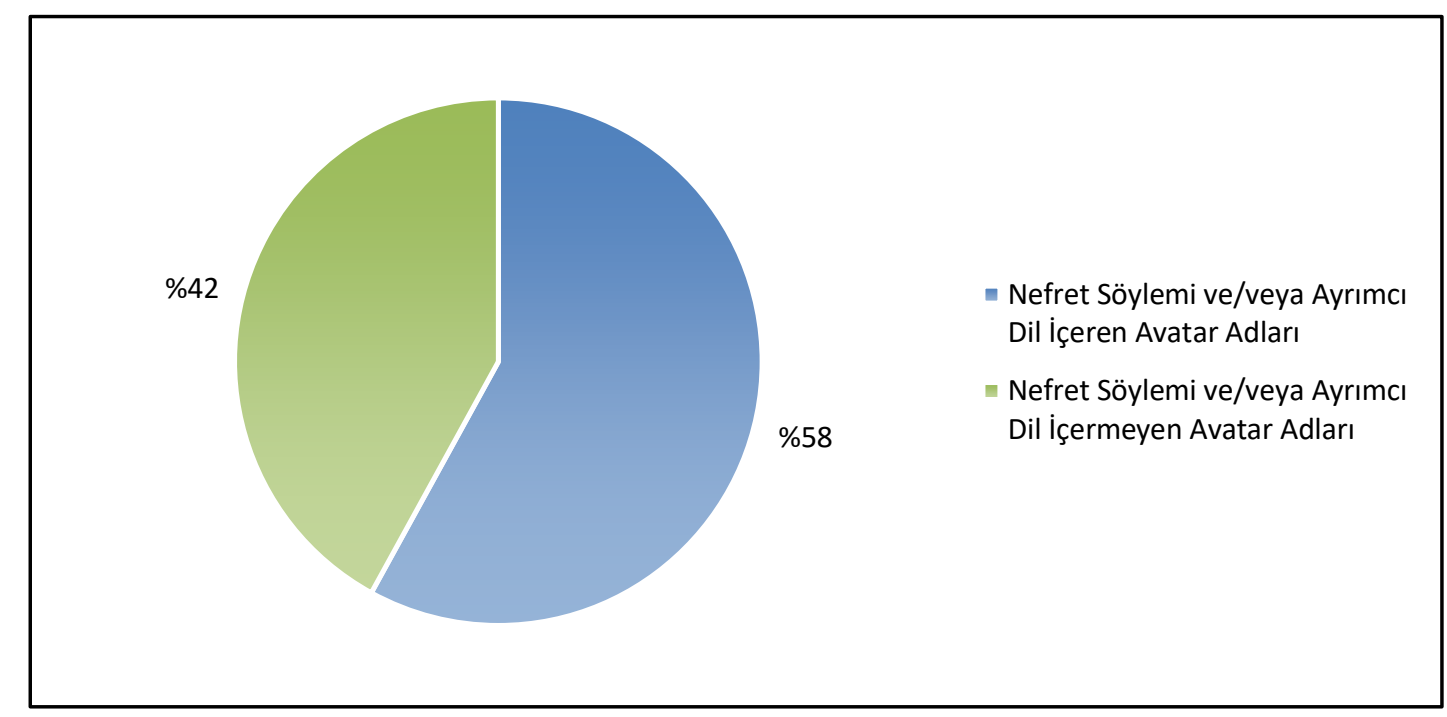

Grafik 2: Avatar Adlarının Nefret Söylemi ve/veya Ayrımcı Dil Türlerine Göre Dağılımı

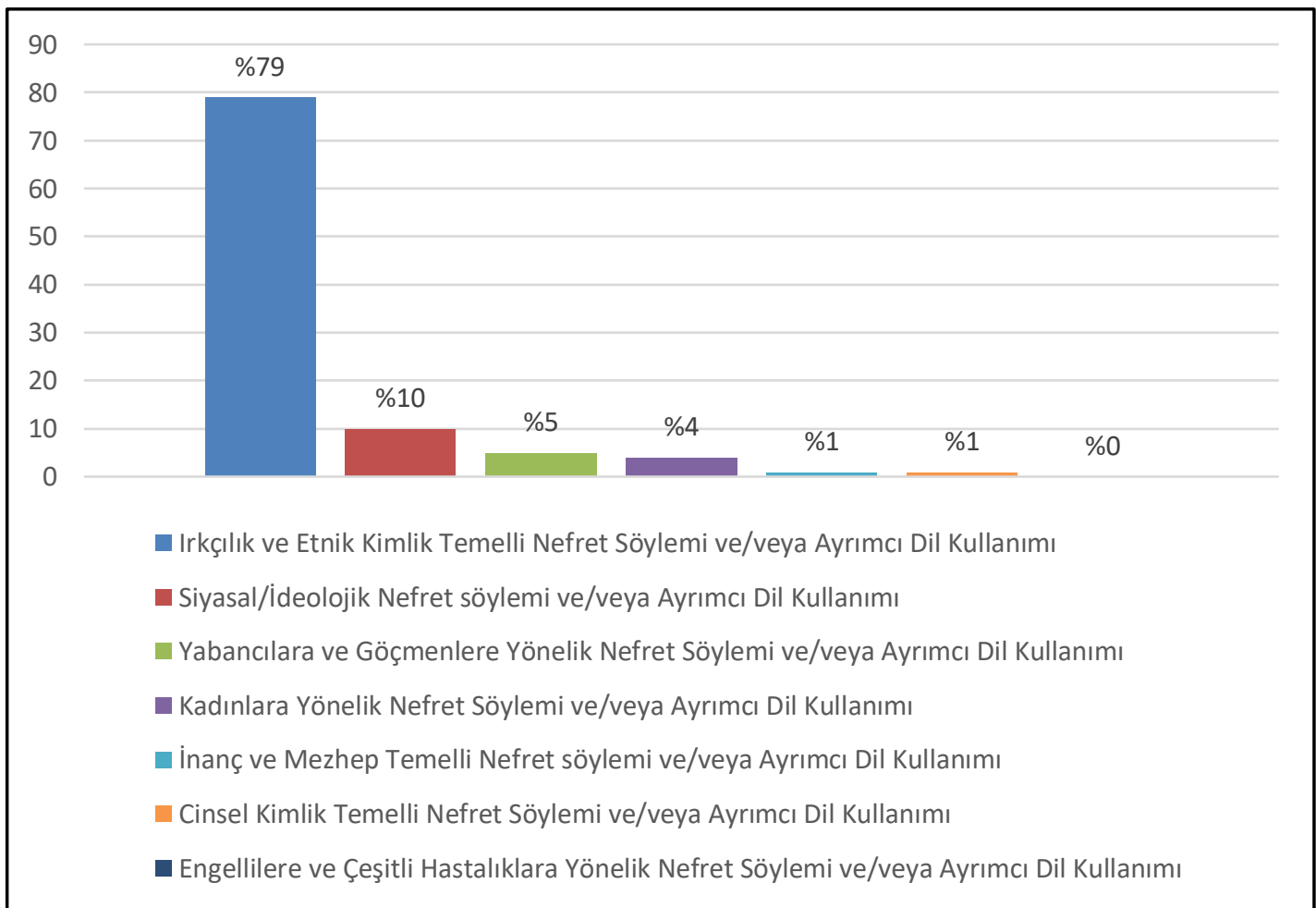
alınmıştır.

Tespit edilen nefret söylemi ve/veya ayrımcı dil kategorileri aşağıda başlıklar halinde ele

\footnotetext{
${ }^{15}$ Çalışmada, örnek olarak paylaşılan avatar adlarında yer alan küfürlerde “*” sembolü kullanılmış; küfür içerikli görseller ise kısmen mozaiklenmiştir.
} 


\subsubsection{Irkçılık ve Etnik Kimlik Temelli Nefret Söylemi ve/veya Ayrımcı Dil Kullanımı}

Oyunda en fazla karşılaşılan nefret söylemi ve/veya ayrımcı dil kullanımı \%79 gibi yüksek bir oranla ırkçılık/etnik kimlik temelli nefret söylemi ve/veya ayrımcı dil grubuna aittir. Oyuncuların, belirli nedenlerle aidiyet hissettikleri etnik kimliklerini ifade etme çabaları, sürekli bir karşıtlığın ortaya çıkmasının nedeni olarak görülmüştür. Avatar adı ya da görseli olarak etnik kimliğini belirten oyuncular, diğer oyuncu avatar adlarındaki nefret söylemi ve/veya ayrımcı dilin hedefi haline gelmiştirler. Kendilerini oyunda etnik kimlikleriyle (Kürt, Türk, Laz, Çerkez, Azeri) ifade etmeye çalışan oyuncuların avatar adlarına karşı diğer oyuncuların, saldırıda/misillemede bulunmak amacıyla, hedefteki söz konusu avatar adlarının başına ya da sonuna hakaret ya da argo kavramlar içeren kelimeler ekleyerek yeni avatar adları oluşturdukları tespit edilmiştir. Bu anlamda oyuncuların birbirlerine mesaj vermeleri suretiyle karşıllklı bir konumlandırmanın ortaya çıktığı görülmüştür. Örneğin oyunda "Kürt", "Kral Kürt”, "Solo Kürd”, "Kürdo", "Jumbo Kürt", "Kürt k1z121", "KürtCHE”, "Büyük Kürt", "Tek Kürt", "Ulu Kürt", "Kürdistan” gibi isimler avatar adı olarak çoğaldıktan bir süre sonra, "Kürte Giren”, "Kürde2Sürt1Dürt”, "Kürt Avcısı", "Kürde Sok”, “Amk Kürdü”, "KürtSavar", "Kıro kürt”, "Kürt Kanırtan”, "Kürdo öpen Laz”, "Kürde Ölüm”, "Kürde kayan", "Kürtün anasını...", "kürtbüken", "Kodumun Kürdü”, "Kürt anırtan", "Kürt S*ken" şeklinde nefret söylemi ya da ayrımcı dile sahip avatar adlarının arttığı görülmüştür. Yukarıdaki örneklerde de açıkça görüldüğü üzere etnik kimlik temelli nefret söylemleri, hedefteki etnik kimliğe eklenen olumsuz nitelemelerle gerçekleştirilmiştir.

Benzer şekilde aynı durumun Türk'e, Türklüğe ya da Türkiye'ye atıfta bulunan avatar adları için de geçerli olduğu görülmüştür. Örneğin "Türk Geldi”, "Türksen Övün” "Türkiyem”, "Çılgın Türk”, “Türk Gücü”, "Türk Takımı”, “Asil Türk”, “Türk Boyun Eğmez”, "Türkü Yeme O.Ç.”, "Türk Çocuğu", "Türküz Koçum”, "TürkKızı", "Çıllgın Türk”, "Türke itaat et”, "Türke Selam Dur”, "The Türk", "Türk Sevgisi”, “Türkün gücü”, "Türkoğlu Türk", "Ne Mutlu Türke”, "Ne mutlu Türküm”, "Şanlı Türk” şeklindeki avatar adlarına karşı "Türk s*ken Kürt”, "Türk Vurucu”, "Türke parmak at”, "Piç Türk", "Türke koyam", "Türk s*ken”, "Türk avcısı", "AMK Türkü”, “Türk hoplatan” şeklindeki avatar adlarının arttığı tespit edilmiştir. Örneklerden de anlaşılabileceği üzere irkçılık ve etnik kimlik temelli nefret söylemi çoğunlukla Kürt ve Türk 1rkçılığı üzerinden üretilmiştir.

Yukarıda ifade edildiği şekliyle ırkçılık kapsamında değerlendirilebilecek avatar adları dışında belirli bir şehre ya da bölgeye atfen kullanılan "42 Konya", "Adanalıyıh", "Angaralı", "Erzurum", "Sinop", "73 Şırnak 73", "Güzel Şehir 35"16 gibi adları hedef alan ve belirli bölgeler için ayrımcı dile sahip avatar adlarına da rastlanmıştır. "Konyayı bombala", "Konyanın manyağı", "Doğulu kırolar”, "İbne Bursalı", "Dümbük Adanalı", "Mal Konyalı", "Doğu Keko dolu”, "Kırolar doğuya", "Gavur İzmir" gibi örneklerde nefret söylemi ve/veya ayrımcı dilin avatar adlarına yansıdığ 1 tespit edilmiştir. Bu çerçevede tespit edilen bazı avatar adları ve görselleri şekil 1'de verilmişstir.

${ }^{16}$ Avatar adlarında kullanılan rakamlar genellikle şehir plaka numaralarını ifade etmektedir. 
Şekil 1: Irkçılık/Etnik Kimlik Temelli Nefret Söylemi ve/veya Ayrımcı Dil Grubuna Ait Bazı Avatar Örnekleri

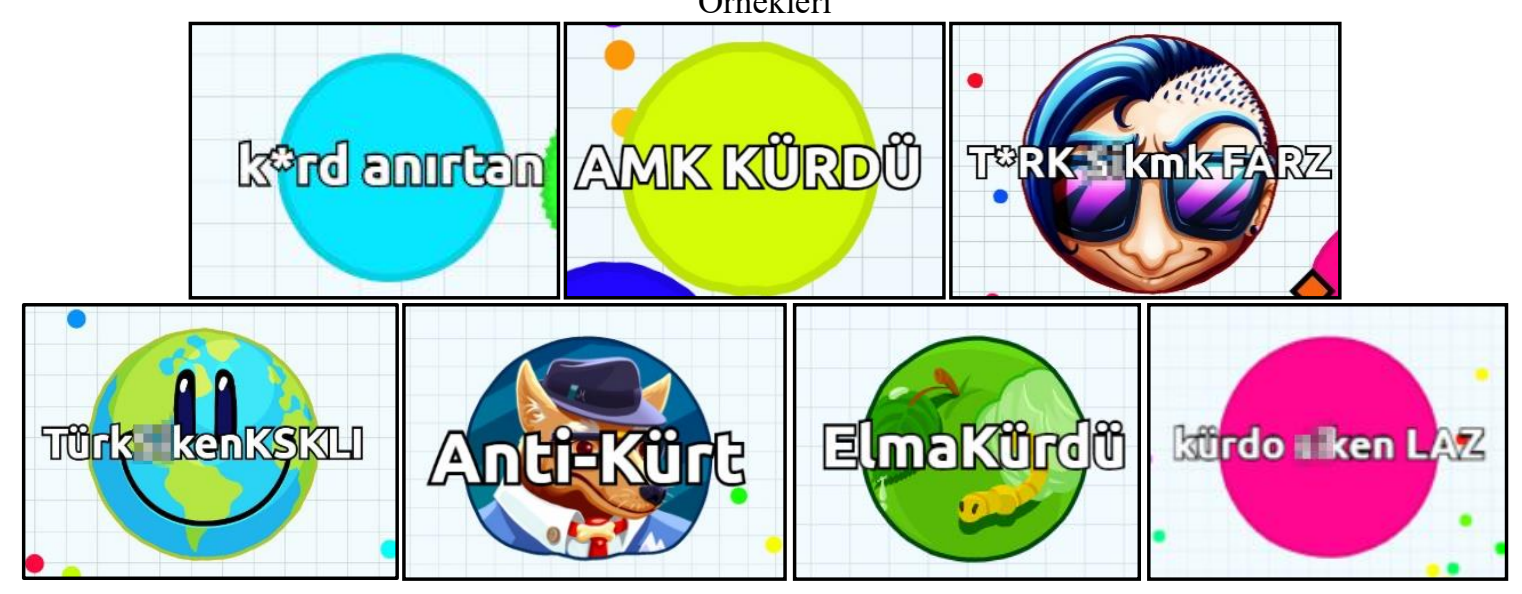

5.1.2. Siyasal/İdeolojik Nefret söylemi ve/veya Ayrımcı Dil Kullanımı

Oyunda, nefret söylemi ve/veya ayrımcı dil kullanımı bağlamında karşılaşılan ikinci kategori ise \%10'luk bir oranla siyasal/ideolojik nefret söylemi ve/veya ayrımcı dildir. Oyuncular, oyun alanını siyasal bir arenaya dönüştürmek suretiyle kendi siyasal/ideolojik yaklaşımlarını ifade etmeye çalışmışlardır. Bu çerçevede bazı oyuncular da genellikle karşıt siyasal/ideolojik düşüncelere, yaklaşımlara saldırmak amacıyla nefret söylemi ve/veya ayrımcı dil kullanmışlardır. Bu anlamda bir önceki başlıkta değinilen ırkçılık/etnik kökene dayalı nefret söylemi ve/veya ayrımcı dil kullanımıyla siyasal/ideolojik nefret söylemi ve/veya ayrımcı dil kullanımı, oluşturulma amacı çerçevesinde birbiriyle benzerlik göstermektedir. Özellikle bazı illerde yenilenen 2 Haziran 2019 yerel seçim döneminde daha yoğun bir șekilde karșlașılan ve siyasal, ideolojik yaklaşımların ifade edildiği "Bozkurt”, "Ülkücü”, “Ülküdaş”, "Ülkücü Birlik”, “Asena58”,"Ülkücü Bayan”, “Turan”, "Ülkü ocakları", "Kızıl elma", "Börteçine”, "Börü”, "Ulu Türk”, "Reis", "Ülkücü gençlik” gibi milliyetçi kavram ve semboller; "Devrim", "Dewrimci", "BYN Sosyalist", "Yoldaş", "Komünist Başkan", "Komünist Burada", "TR Devrim", "Devrimciyiz", "Komünist” gibi farklı derecelerdeki sol eğilimli görüşler; "Kemalist", "Atatürk", "Atatürkçü", "Ulu önder", "Yüce Atatürk", "Mustafa Kemal”, "Gazi M.K." gibi Atatürkçü/Kemalist yaklaşımlar; "AKP”, "AK Parti”, "İnadına AKP”, "CHP”, "MHP", "HDP", "İyi Parti", "TKP" gibi siyasal parti isimleri; "Muharrem İnce", "RTE", "İmamoğlu", "Binali Yıldırım", "Selahattin Demirtaş", "Başbuğ Türkeş", "M. Yazıcıoğlu" gibi siyasetçi isimleri; "Millet ittifakı", "Cumhur İttifakı" gibi siyasal ittifaklar sıklıkla oyunda avatar adı olarak tercih edilmiştir. Yukarıda bahsedilen bu gruplardan farklı olarak siyasal/ideolojik temsil aracı bağlamında tercih edilen bazı avatar adlarını "Führer", "Lenin", "Marx", "Yılmaz Güney" şeklinde sıralamak mümkündür. Ayrıca "Apo", "Öcalan”, "Abdullah Çatlı", "PKK”, "PKK aşktır", "PYD”, "IŞID", "Işidciyiz", "Daeş", "Mahir Çayan", "Deniz Gezmiş̧" gibi yasadışı, aşırı uç ya da terörist kabul edilen kişi ya da örgüt isimlerinin de avatar adı olarak kullanıldığ tespit edilmiştir.

Yukarıda belirtilen avatar adlarına siyasal/ideolojik çerçevede nefret söylemi ve/veya ayrımcı dil kullanarak saldıran avatar adlarına da rastlanmıştır. Örneğin "Ülkücü Avcısı", "Ülkücüye vur", "Ülkücü s*kici”, "Faşo MHP”, "Faşizme geçit yok" gibi milliyetçi ideolojiye; "Solcu pislik", "Sola sokam", "Devrimine koyam", "AMK Komünisti" gibi farklı eğilimlerdeki sol görüşlere; "Atatürk S*ken", "Atatürke koyam", "Laik s*kici", "Kemalist Pzv" gibi Atatürkçü/Kemalist ideolojiye; "AKP'li S*ken", "Beyinsiz AKPli", "CHP'li s*keyim", "Hırsiz chpkk", "CEHAPE=PKK=BOK", "SanaFaziletKor", "Mal CHPli", "Dinsiz CHP”, "Beyinsiz CeHaPe", "İt 
soyu CHP”, "HDPye sokam" gibi siyasal partilere; "Zillet ittifakı", "İlet ittifakı" gibi siyasal ittifaklara karşı nefret söylemi ve/veya ayrımcı dil kullanan avatar adları tespit edilmiştir. ${ }^{17}$

Avatar adı olarak bazı șehirlerin resmi olarak kullanılan Türkçe isimlerinin yerine, Kürtçe isimlerinin kullanıldığı görülmüştür. Örneğin Diyarbakır yerine Amed, Tunceli yerine Dersim gibi simgesel isimler tercih edilmiştir. Başka oyuncular ise bu isimlere "Amedinize koyam", "Dersiminiz batsn" şeklindeki avatar adlarıyla karşılık vermişlerdir.

Siyasal/ideolojik nefret söylemi ve/veya ayrımcı dil çerçevesinde tespit edilen bazı avatar adları ve görselleri şekil 2'de verilmiştir.

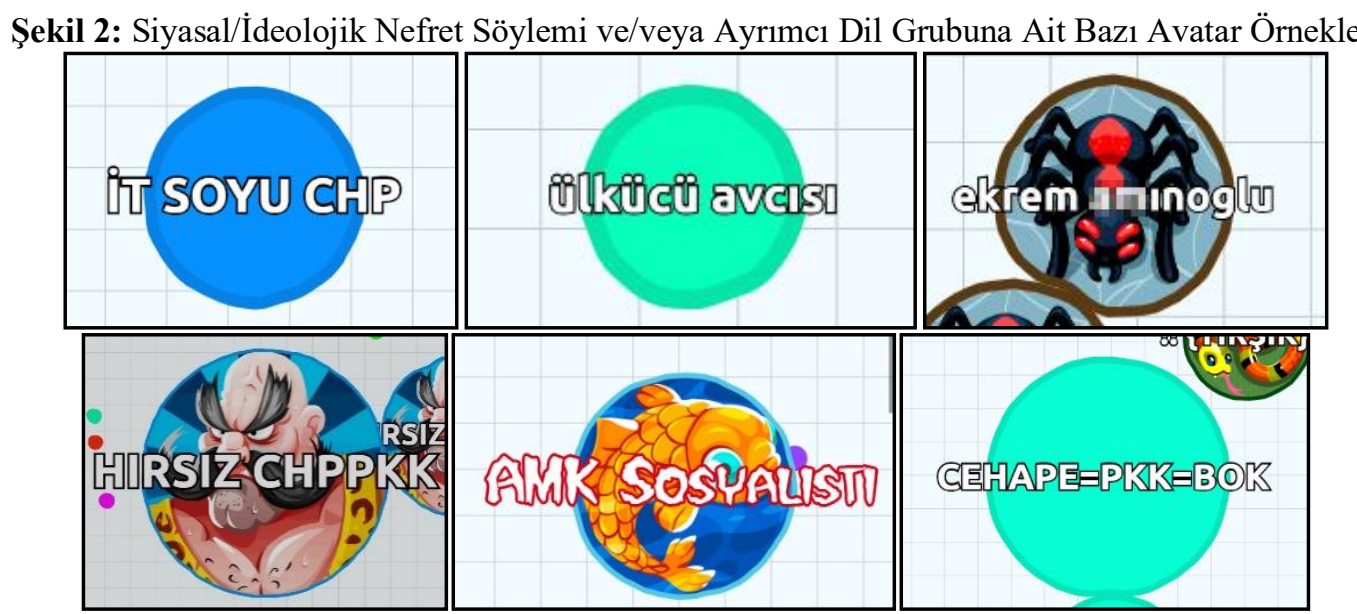

\section{Kullanımı}

\subsubsection{Yabancılara ve Göçmenlere Yönelik Nefret Söylemi ve/veya Ayrımcı Dil}

Oyunda yabancılara ve göçmenlere yönelik gerçekleştirilen nefret söylemi ve/veya ayrımc1 dil kullanımı $\% 5$ olarak tespit edilmiştir. Bu kategoride yer alan nefret söylemi ve/veya ayrımcı dile sahip avatar adlarının ilk iki bölümde ele alınan karşıt konumlandırma yani diğer avatar adlarına tepki verme biçiminde ortaya çıkan nefret söylemi ve/veya ayrımcı dil kullanımlarından farklı olduğu görülmüştür. Anaakım medyada sıklıkla yer alan göçmen ve yabancılarla ilgili haberlerin, oyuncuların mesajlarına da yansıdığı; göçmenlere ve yabancılara yönelik gerçekleşen nefret söylemi ve/veya ayrımcı dil kullanımının, anaakım medyanın ve dolayısıyla kamuoyunun gündemine paralel şekilde arttığ 1 tespit edilmiştir.

Bu kategorideki nefret söylemi ve/veya ayrımcı dilin başlıca hedefi, Türkiye'deki göçmen nüfusun çoğunluğunu oluşturan Suriyeli göçmenlerdir. Suriyeli göçmenlere yönelik nefret söylemi ve/veya ayrımcı dil içeren avatar adlarının bazılarını "Suriyeliye koyam", "Her yer Suriyeli", "Piç Suriyeliler", "Suriyeli giremez", "Suriyeli Defol", "Herkes ülkesine", "AMK suriyelisi" şeklinde sıralamak mümkündür. Araştırmanın yapıldığı dönemde Rus S-400 hava savunma sistemi ve Amerikan F-35 savaş uçaklarıyla ilgili tartışmaların medyanın gündeminde sıklıkla yer alması, konunun aktörlerine yönelik nefret söylemi ve/veya ayrımcı dil kullanımını da arttırmıştır. Örneğin "aditrump", "S400girsinABDye", "SSerefsiz USA", “ABD s*ken”, "Al F35ni sok...", "O.Ç ABD” şeklindeki avatar adları bunlardan bazılarıdır. Ayrıca Türklerin tarihsel olarak düşman saydığı ve kalıpyargılar geliştirdiği Yunanlılar, İngilizler, Araplar, İsrailliler de bu kategorideki nefret söylemi

17 Zillet ittifakı ve İllet ittifakı gibi ayrımcı söylemlerin ilk kez siyasi parti liderlerince kullanılması ve sıklıkla tekrar edilmesinin, nefret söylemi ve ayrımcı dil kullanımında kötü bir örnek ve pekiştireç olduğu tahmin edilmektedir. Bu anlamda siyasetçilerin söylemlerindeki nefret içeriklerinin ve ayrımcı dil kullanımının toplum nezdinde bu türdeki söylemlerin normalleşmesine, sıradanlaşmasına ve yaygınlaşmasına neden olduğunu belirtmek gerekir. 
ve/veya ayrımcı dilin hedefi haline gelmişlerdir. "Yunan tohumları", "İngiliz uşağı", "Pis Arap", "Yavşak İsrail" gibi avatar adları bu çerçevede örnek verilebilir.

Yabancılara ve göçmenlere yönelik gerçekleştirilen nefret söylemi ve/veya ayrımcı dil kapsamında tespit edilen bazı avatar adları ve görselleri şekil 3’te verilmiştir.

Şekil 3: Yabancılara ve Göçmenlere Yönelik Nefret Söylemi ve/veya Ayrımcı Dil Grubuna Ait Bazı Avatar

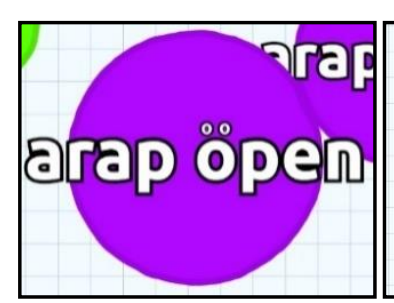
Örnekleri

\subsubsection{Kadınlara Yönelik Nefret Söylemi ve/veya Ayrımcı Dil Kullanımı}

Kadınlara yönelik nefret söylemi ve/veya ayrımcı dil içeren avatar adlarının toplam sayıya oranı \%4'tür. Bu kategoride tespit edilen nefret söylemi ve/veya ayrımcı dil kullanımının, erkek egemen kültürde kadının toplumsal rolü ve konumu üzerinden gerçekleştirildiği görülmüştür. Dolayısıyla bu kategorideki avatar adlarının, herhangi bir oyuncuya cevap vermekten ya da sataşmaktan ziyade oyuncuların kadınlara bakış açısını ve yaklaşımlarını ortaya koyduğu söylenebilir. Ağırlıklı olarak cinsel içerikli, aşağılayıcı ve küfür içeren ifadelerin kullanıldığı bu kategorideki bazı avatar adları şöyledir: "BacıDomaltan", "Avrad s*ken", "Ananızı s*kiyim", "Ananı getir", "Bacın gelsin", "Hatunlara Kamış", "Kızlık bozan”, "Kahpe s*ken”, "Or**u özlem”, "Aylin s*ken", "Anana koyam", "ataduravratavur", "anana geliyom", "bekaret avcisı", "hatun gümletici", "kıza kayan”, "kadın kanırtan", "Bacı Dürten", "Bacı Kaldıran”. Bu çerçevede tespit edilen bazı oyuncu avatar adları ve görselleri şekil 4 'te verilmiş̧tir.

Şekil 4: Kadınlara Yönelik Nefret Söylemi ve/veya Ayrımcı Dil Grubuna Ait Bazı Avatar Örnekleri

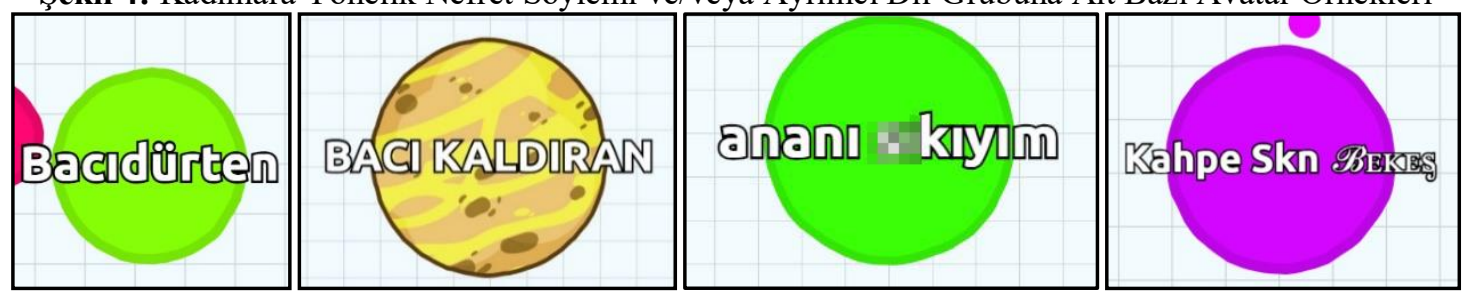

\subsection{5. İnanç ve Mezhep Temelli Nefret söylemi ve/veya Ayrımcı Dil Kullanımı}

Çalışmada, oyuncuların inanç ve mezhep temelli kimliklerini avatar adı olarak kullandıkları da görülmüştür. İnanç ve mezhep temelli nefret söylemi ve/veya ayrımcı dil içeren avatar adlarının oranı \%1'dir. İnanç ve mezhep temelli kimliklerini ifade etmek isteyen oyuncuların "Hayırlı Cumalar", "Davamız İslam", "Hak din İslam", "Tevhid daveti", "Aleviyiz Canlar", "Alevi 58", "Aleviyiz Aslan", “Tek Yol İ́slam", "Sünni Türk", "Ehli İman”, "Deist”, "Namaz Saatiiiii” gibi avatar adlarını tercih ettikleri gözlemlenmiştir. Ancak burada da birinci ve ikinci kategorilerde olduğu gibi, başka oyuncu adlarına karşı bir tepki olarak nefret söylemi ve/veya ayrımcı dilin kullanıldığı görülmüştür. Bu çerçevede erkek Müslümanların ibadet ederken kullandıkları takkeyi hedef alan "takkeli pzv", dini tarikat ve benzeri grupların yöneticisi olarak düşünülen şeyhlerle ilgili 
"şeyim şeyh oldu" şeklinde avatar adları kullanılmıştır. Bunlarla birlikte "aleviye itekle", "kızılbaş=alevi" gibi avatar adlarıyla Alevilere yönelik de nefret söylemi ve ayrımcı dil geliştirilmiştir. Bu çerçevede tespit edilen bazı oyuncu avatar adları ve görselleri şekil 5'te verilmiştir.

Şekil 5: İnanç ve Mezhep Temelli Nefret Söylemi ve/veya Ayrımcı Dil Grubuna Ait Bazı Avatar Örnekleri

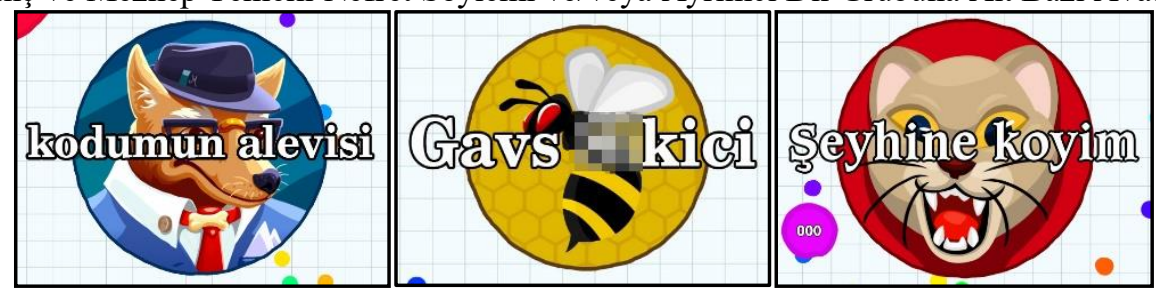

\subsubsection{Cinsel Kimlik Temelli Nefret Söylemi ve/veya Ayrımcı Dil Kullanımı}

Başkalarının cinsel kimliklerine ve tercihlerine yönelik nefret söylemi ve/veya ayrımcı dil içeren avatar adlarının oran $1 \% 1$ olarak tespit edilmiştir. Az sayıda da olsa oyuncuların kendi cinsel kimliklerini ve tercihlerini ifade ettikleri "Gay", "Travesti”, "Lezbiyen", "Lez Femme" gibi avatar adları görülmüsşür. Bu tür avatar adlarının azlığına karşın cinsel kimlikler ve tercihler üzerinden üretilen nefret söylemi ve/veya ayrımcı dilin daha fazla oluşu dikkat çekicidir. Bu bağlamda yer alan bazı avatar adlarını "Travestikatili", "İbne s*ken", "lan ibneler", "Gay Vurucu" şeklinde sıralamak mümkündür.

30 Haziran 2019 tarihinde LGBTI'lerin İstanbul'da yapmak istedikleri “Onur Yürüyüşü”nün bazı kitle iletișim araçlarında gündem olması, oyuncuları da etkilemiș ve bu konudaki nefret söylemi ve/veya ayrımcı dil, avatar adlarına da yansımıştır. Genellikle 'onur' kavramı üzerinden türetilen ve nefret söylemi ve/veya ayrımcı dil kullanımı içeren bazı avatar adları "Onursuz yürüyüşs", "Onurunuza sokam", "Göt LGBT", "Onurluymuş :)", "Yürüyün ibneler", "Bana yürüme de...", "Cehenneme yürü" şeklindedir. Bu çerçevede tespit edilen bazı oyuncu avatar adları ve görselleri Şekil 6'da verilmiştir.

Şekil 6: Cinsel Kimlik Temelli Nefret Söylemi ve/veya Ayrımcı Dil Grubuna Ait Bazı Avatar Örnekleri
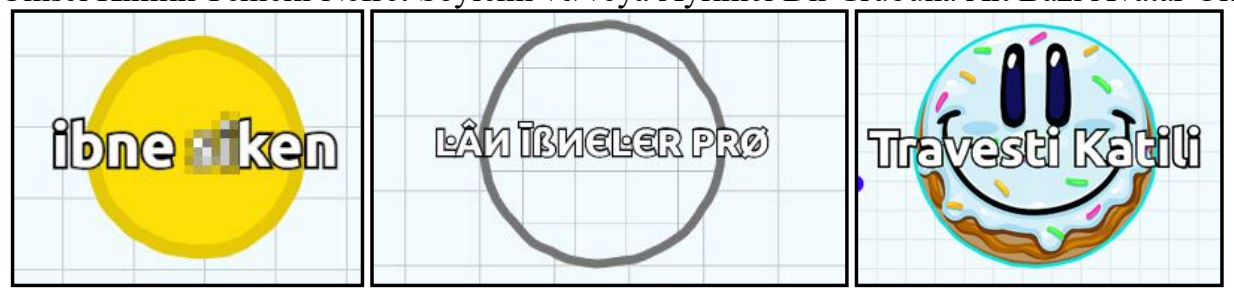

\subsection{Avatar Görselleri}

Oyuncuların avatar adlarında yoğun bir şekilde siyasal, kültürel, etnik, dini, vb. içerik görülmesine karşın avatar görsellerinde aynı yoğunluk söz konusu değildir. Avatar adları değerlendirme dışı bırakılarak sadece avatar görselleri üzerinden bir değerlendirme yapıldığında, oyuncuların \%72'sinin siyasal, kültürel, etnik, cinsel ve dini kimliklerine ilişkin herhangi bir paylaşımı görülmemiştir. Gerek yeni görsellerin oluşturulmasının zorluğu gerekse bu işlemin ek vakit alması sebebiyle oyuncuların mesajlarını ağırlıklı olarak avatar adları üzerinden vermeye çalıştıklarını söylemek mümkündür. Geriye kalan \%28'lik dilimde yer alan oyuncuların avatar 
görsellerinin daha önce belirtilen çerçevede mesaj verme amacı güttüğü görülmüştür. Mesaj verme kaygısı taşıyan avatar görsellerinin büyük bir kısmının avatar adlarıyla uyumlu olmasına karşın sadece avatar görsellerinin değerlendirilmesiyle nefret söylemi ya da ayrımcı dile dayalı güçlü tespitlerin yapılamayacağı kanaatine varılmıştır. Bu nedenle, oyuncuların avatar görsellerini avatar adlarını destekleyecek şekilde oluşturdukları/seçtikleri ve söz konusu görsellerin sadece avatar adlarıyla birlikte ele alındığında bir anlam taşıyacağı söylenebilir.

Avatar görsellerinde karşılaşılan mesaj içerikli sembollerin iki farklı şekilde kullanıldığ tespit edilmiştir. Birinci gruptakiler avatar adının başına ve/veya sonuna eklenen sembollerdir. Diğer sembollerse doğrudan avatar resimleri/skinleri olarak karşımıza çıkmaktadır. Avatar adlarındaki görsellerde en sık karşılaşılan semboller zafer işareti, üç hilal, ay yıldız, orak-çekiç, bayraklar, flamalar, k1lıç sembolleri, silah sembolleri, yıldız, hilal, kurt başı, kuru kafadır. Bu sembollerle avatar adları birlikte ele alındığında daha anlamlı bir tablo ortaya çıkmaktadır.

Avatar adlarındaki sembollerden hilalin göstereni olarak tek "C" harfiyle İslam dinine; üç hilalin göstereni olarak yan yana kullanılan üç " $C$ " harfiyle (CCC) milliyetçiliğe, Türk bayrağının göstereni olarak " $\mathrm{C}$ " harfi ve “*” (yıldız) işaretlerinin birlikte kullanılmasıyla $\left(\mathrm{C}^{*}\right)$ Türkiye Cumhuriyeti'ne, sosyalizmin/komünizmin göstereni olarak orak ve çekiçle sosyalist/komünist ideolojiye, kurt ve kurt başı sembolleriyle milliyetçiliğe/MHP'ye gönderme yapılmıştır. Bazı avatar görsellerinde ise avatar adlarıyla birlikte \# işaretine yer verilmiştir. Oyuncuların bu yolla, bir sosyal medya mecrası olan Twitter'daki bir gündeme ya da başlığa destek vermeye çalıştıkları çıkarımı yapılabilir. Bu çerçevede değerlendirilebilecek bazı avatar görselleri ve Leaderboard'da yer alan avatar ad görselleri şekil 7'de verilmiştir.

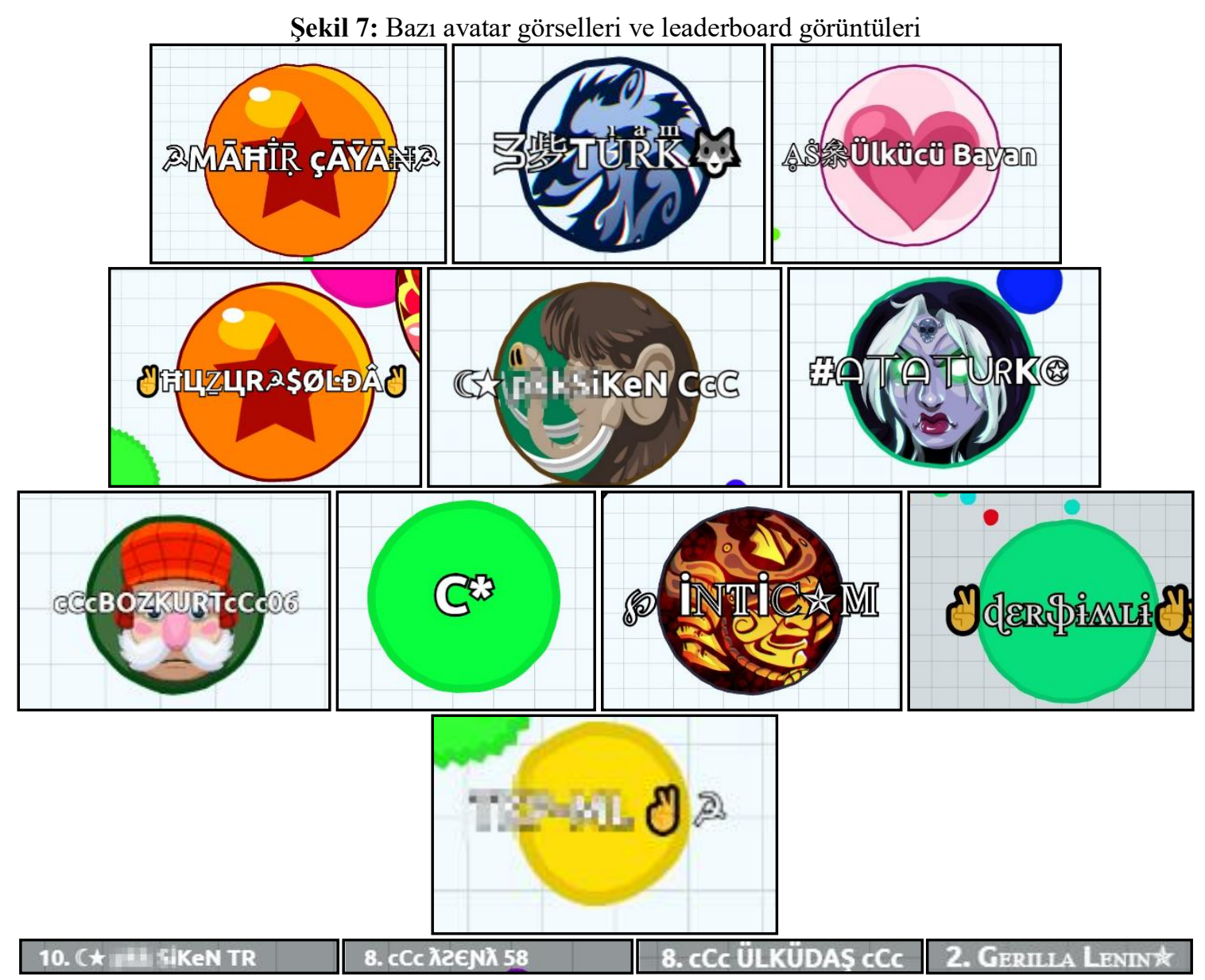

Turkish Studies - Social, 15(1) 


\section{Sonuç}

Online dijital oyunlarda nefret söylemi ve ayrımcı dili konu alan bu araştırmada, örneklem olarak seçilen Agar.io oyunundaki oyuncuların \%87'sinin kendini siyasal, etnik, kültürel, cinsel, dini kimliği ve değerleri üzerinden ifade etmeye çalıştığı tespit edilmiştir. Avatar adlarında ve görsellerinde genellikle milliyetçi ve erkek egemen söylemlerin ağırlıklı olduğu görülmüştür. Bu bağlamda çalışmanın başında ortaya konan "MMOG türü oyunlarda oyuncular siyasal, kültürel, etnik, dini, vb. bireysel mesajlar verme kaygısı taşımaktadırlar ve online oyunlanı mesaj verebilecekleri bir ortam olarak görmektedirler" hipotezini destekleyen bulgulara ulaşılmıştır.

Avatarları üzerinden mesaj verme kaygısı taşıyan oyuncuların \%58'lik kısmının nefret söylemi ve/veya ayrımcı dil içerikli mesajları paylaştıkları tespit edilmiştir. Bu tür oyunlardaki mesaj verme kaygısının oyun içi rekabetle birleştiğinde, kasıtlı ya da kasıtsız nefret söylemi ve/veya ayrımcı dile kayan bir içeriğe bürüdügü, dolayısıyla da söz konusu söylemlerin gündelik dilin doğal bir parçası haline gelerek sıradanlaştığı ve sürekli göz önünde bulunarak normalleştiği sonucuna ulaşılmışıı. Bu açıdan "MMOG türü oyunlarda oyuncuların mesaj verme kaygısı genellikle nefret söylemine ya da ayrımcı dile kayan aşırılıklara neden olmaktadır" hipotezi doğrulanmaktadır. Bu bağlamda oyun içi iletişim araçları bulunmamasına rağmen oyuna dair her türlü enstrümanın oyuncular tarafından mesaj verme amacıyla kullanılabileceğini ve bu mesajların nefret söylemi gerçekleştirebilecek bir araç haline gelebileceğini iddia eden, "MMOG türü oyunlarda oyuncular, avatar görseli ve avatar ad seçimleriyle herkese açık görsel/sözel nefret söylemi üretmektedirler" hipotezini doğrular nitelikte verilere de ulaşılmıştır.

Oyuncuların bir gruba ait olma, birliktelik gibi duygular nedeniyle benzer siyasal, ideolojik, etnik, dini, vb. değerlere sahip diğer oyuncularla iş birliği yaptıkları; gruplar oluşturdukları ve karşıt görüşteki oyuncularla takımlar halinde mücadeleye giriştikleri; oyun oynamanın yanında mesaj verme, diğer gruplara ideolojik, siyasal, sosyal vb. üstünlük sağlama çabasında oldukları gözlemlenmiştir. Bu da online dijital oyunların, oyuncuların aidiyet duygusunu ve sosyal kimliğini pekiştiren ortamlar olduğu fikrini desteklemektedir.

Yapılan incelemelerde nefret söylemine ilişkin Binark ve Çomu'nun (2012) oluşturduğu "hedef aldığı gruba göre nefret söylemi türleri”den siyasal nefret söylemi, yabancılara ve göçmenlere yönelik nefret söylemi, kadınlara yönelik nefret söylemi, inanç ve mezhep temelli nefret söylemi, cinsel kimlik temelli nefret söylemi türlerinde bulgulara ulaşılmıştır. Söz konusu türlerden sadece engellilere ve çeşitli hastalıklara yönelik nefret söylemi örneğine hiç rastlanmamıştır. Gözlem sonucu elde edilen veriler, "irkçılık ve etnik kimlik temelli nefret söylemi ve/veya ayrımcı dil" olarak yeni bir kategorinin eklenmesi zorunluluğunu ortaya çıkarmıştır. Bununla birlikte çok nadir de olsa farklı meslek gruplarını hedef alan nefret söylemi ve/veya ayrımcı dil örneklerine rastlanmıştır. Bunlara, "avukat patlatıcı", "salak mühendis", "gerzek doktor", "mal öğretmen”, "dingil polis" şeklindeki avatar adlarını örnek vermek mümkündür. ${ }^{18} \mathrm{Bu}$ bağlamda "MMOG türü oyunlarda nefret söyleminin farklı türlerine rastlanmaktadır" hipotezi doğrulanmıştır.

Çalışmanın başında ortaya konan "Ülke gündemindeki konular, MMOG türü oyunlara da yansıyarak oyundaki mesaj içeriklerini etkilemektedir" hipotezini doğrulayan verilere de ulaşılmış, kamuoyu ve medya gündeminin oyuncuların gündemini belirlediği görülmüștür. Anaakım medyanın gündemi paralelinde verilen mesajlara ve yine bu doğrultuda ortaya çıkan farklı nefret söylemi türlerine rastlanmıştır. Çalışmanın yapıldığı dönemde Yüksek Seçim Kurulu tarafından bazı seçim bölgelerindeki yerel seçimlerin yenilenmesi kararının ardından oyuncuların avatar görselleri ve adları siyasal gündem paralelinde değișmiş; parti isimlerinin yerine aday isimlerinin daha ön plana çıktığı tespit edilmiştir. Siyasal mesaj içerikli avatar adlarının \%76'sı Binali Yıldırım'a ya da Ekrem İmamoğlu'na atıf yapacak şekilde (B. Yıldırım, Yıldırım, Binali ve türevleri, E. İmamoğlu,

${ }^{18}$ Bu kategoriye giren örneklerin \%1'den az olması sebebiyle ayrı bir başlık açılmasına gerek duyulmamıştır. 
İmamoğlu, Ekrem ve türevleri) belirlenmiştir. \%12'si "YineKazanacağız”, "Çalmak yok”, “İstanbul bizim" gibi slogan içeren avatar adlarından oluşmuştur.

Veri toplamada kullanılan katılımlı gözlem tekniği sayesinde, oyunda geçirilen zaman içerisinde çalışmanın hipotezlerinden bağımsız olarak gözlemlenen bazı önemli noktalar da bulunmaktadır. Herhangi bir nefret söylemi ya da ayrımcı dil kategorisine girmese de oyun içerisinde bazı oyuncuların yasadışılığa varan aşırı uçlardaki siyasal/ideolojik görüşlerini oyun içerisinde rahatlıkla ifade ettikleri görülmüştür. Bu çerçevede oyuncuların yasadışılığa varan farklı mesaj içeriklerini, kendilerini ifade etme adına paylaşabilecekleri farklı yollar bulabildikleri tespit edilmiştir. Örneğin bazı avatar adlarında ve görsellerinde suç, terör gibi olgularla ilişkilendirilen ve yasadış1 olarak kabul edilen kişi, grup ya da örgütlerin isim ya da görsellerinin sıkl1kla kullanıldığ1 tespit edilmiştir. Söz konusu bu kişi, grup ya da örgüt sempatizanlarının toplumda daha çok görünür olma, dikkat çekme ve propaganda yapmak amacıyla bu mecrayı kullandıkları tahmin edilmektedir. $\mathrm{Bu}$ çerçevede "PKK", "PYD", "PKK-PYD”, "YPG-PYD", "Aşk=PKK=21", "PKK Kürdistan", "Gerilla", "KCK”, “TKP-ML”, “TC s*ken", "Pkk halktır", "PKK Geldi”, "Yaşa Daeş” şeklindeki avatar ad ve görsellerine sıklıkla rastlanmıştır. Daha önce de ifade edildiği üzere diğer oyuncuların, bu avatar adlarına ve görsellerine tepki olarak "Daeş s*kiyoruz", "PKK Domaltan", "PKK avcısı", "Pkk s*ken", "GerilaVuranGazi", "O.ç. pkk", gibi avatar adlarıyla oyuna yeniden giriş yaptıkları gözlemlenmiştir. Benzer biçimde "T.C. Burada", "T.C.", "Devlet Baba", "Jöh"19 , "Pöh"20 , "Polis", "TSK"21 , "Türk Ordusu", "Vatan Bölünmez", "Hain temizleyen" gibi avatar adları da tespit edilmiştir.

MMOG türü oyunların giderek yeni bir tür sosyal medyaya dönüştüğüne dair bazı bulgulara rastlanmıştır. Avatar adlarının ve görsellerinin tweet'ler, DM'ler, storyler, durumlar ve gönderiler gibi sosyal medya kullanım biçimlerine paralel bir şekilde kullanıldığ 1 görülmüsşür. Bu anlamda bakıldığında "Deistim", "boş oturuyom", "Ktü İtü yatay", "Maaş Yattı :)", "Ayrıldım", "Burs Lazım", "Yazlıkçı", "Bahtsızım", "Yaş 44 oldu!" gibi avatar adları örnek olarak verilebilir. Bazı avatar adlarının hashtagli (\#) bir şekilde verilmesi de sosyal medya paralelinde bir kullanım olarak değerlendirilmiştir. Yine benzer anlamda oyunu bir sosyal medya olarak değerlendirerek reklam yapma çabasında olan firmalara rastlanmıştır. "Gül çiçekçilik", "Tek Pen", "İst.Hırdavat", "Lala Cafe" gibi avatar simleri bu türden örnekler içerisinde yer almaktadır. Son bir cümleyle özetlemek gerekirse Agar.io özelinde incelenen MMOG türü oyunlar, oyuncular tarafindan sadece oyun ve eğlence amacıyla değil; aynı zamanda yarışmak, sataşmak, propaganda yapmak, reklam yapmak, sosyal mesaj göndermek, benzer görüştekilerle birlikte olmak ve karşı1 görüşlerle mücadele etmek gibi amaçlarla oynanmakta; ulusal gündemden etkilenen yeni bir sosyal medya ortamı olarak kullanılmaktadır.

Agar.io ve diğer MMOG türü oyunlara tamamen anonim olarak katılabilme imkanının bulunmasının ve denetimden uzak olma hissinin verdiği güven duygusunun, oyuncuları aşırılığa ve yasadışılığa varan mesajları üretip paylaşabilme noktasında cesaretlendirdiği düşünülmektedir. $\mathrm{Bu}$ noktada söz konusu yasadışı1lı̆ın ve ifade aşırılıklarının asgari düzeye çekilebilmesi için, tüm online oyunlara en az bir e-mail hesabı ve en az bir sosyal medya hesabiyla ya da bir cep telefonu numarasıyla doğrulama/ilişkilendirme zorunluluğunun getirilmesi hem oyuncuların otokontrol sağlamaları hem de gerekli durumlarda oyunculara erişilebilmesi açısından bir çözüm önerisi olarak sunulabilir. Nefret söylemi ve ayrımcı dilin dijital oyunların dışında da toplumsal bir problem olması, çözüm önerilerinin de daha geniş bir perspektiften ele alınmasını ve yapısal çözüm önerileri getirilmesini zorunlu kılmaktadır. Bu nedenle bireylerin toplumsal yaşantılarında nefret söylemi ve

\footnotetext{
19 Jandarma Özel Harekât anlamında kullanılmıştır.

${ }^{20}$ Polis Özel Harekât anlamında kullanılmıştır.

${ }^{21}$ Türk Silahlı Kuvvetleri anlamında kullanılmıştır.
} 
ayrımcı dil konusunda bilgilendirmelerine ve farkındalık kazanmalarına yönelik bütüncül adımların atılmas1 gerekmektedir.

\section{Kaynakça}

Abt, Clark C. (1987). Serious Games. Lanham MD: University Press of Amerika.

Adachi, P. J. C. \& Willoughby, T. (2011). The Effect of Violent Video Games On Aggression: Is It More Than Just The Violence?. Aggression and Violent Behavior, 16(1), 55-62. https://doi.org/10.1016/j.avb.2010.12.002

Ağlan, T. C. ve Şensever, F. L. (2010). Ulusal Basında Nefret Suçları: 10 Yıl, 10 Örnek. Sosyal Değişim Derneği.

Anand, V. (2007). A Study of Time Management: The Correlation Between Video Game Usage and Academic Performance Markers. CyberPsychology \& Behavior, 10(4), 552-559. https://doi.org/10.1089/cpb.2007.9991

Apperley, T. H. (2006). Genre and Game Studies: Toward A Critical Approach to Video Game Genres. Simulation \& Gaming, 37(1), 6-23. https://doi.org/10.1177/1046878105282278

Aygül, E. (2010). Facebook'ta Nefret Söyleminin Üretilmesi ve Dolaşıma Sokulması. T. Çomu (Yay. Haz.). Yeni Medyada Nefret Söylemi içinde (s. 95-140). Kalkedon Yayınları.

Banks, J. (2015). Object, Me, Symbiote, Other: A Social Typology of A Player-Avatar Relationships. First Monday, 20(2). https://doi.org/10.5210/fm.v20i2.5433

Banks, J. \& Bowman, N. D. (2016). Emotion, Anthropomorphism, Realism, Control: Validation of A Merged Metric for Player-Avatar Interaction (PAX). Computers in Human Behavior, 54, 215-223. https://doi.org/10.1016/j.chb.2015.07.030

Batı, U. (2011). Sekizinci Sanatın İnşası: Dijital Oyunlar Kesişiminde Postmodernizm, Tüketim Kültürü, Üstgerçeklik, Kimlik ve Olağan Șiddet. G. T. Ünal ve U. Batı (Ed.). Dijital Oyunlar içinde (s. 3-33) Derin Yayınları.

Bayraktutan-Sütcü, G. (2010). Dijital Oyunlarda Cinsiyetçilik. T. Çomu (Yay. Haz.). Yeni Medyada Nefret Söylemi içinde (s. 181-191). Kalkedon Yayınları.

Binark, M. ve Bayraktutan-Sütcü, G. (2008). Kültür Endüstrisi Olarak Dijital Oyun. Kalkedon Yayınları.

Binark, M. ve Bayraktutan-Sütcü, G. (2009). Devasa Çevrimiçi Oyunlarda Türklüğün Oynanması: Silkroad Online'da Sanal Cemaat İnşası ve Türk Klan Kimliği. M. Binark ve diğerleri (Der.). Dijital Oyun Rehberi içinde (s. 275-311). Kalkedon Yayınları.

Binark, M. ve Çomu, T. (2012). Sosyal Medyanın Nefret Söylemi Iç̧in Kullanılması Ífade Özgürlüğü Değildir!. Erişim adresi: http://yenimedya.wordpress.com/2012/01/20/sosyal-medyaninnefret-soylemi-icin-kullanilmasi-ifade-ozgurlugu-degildir/, Erişim tarihi: 17.09.2019.

Bryce, J., Rutter, J. \& Sullivan, C. (2006). Digital Games and Gender. J. Rutter and J. Bryce (Ed.). Understanding Digital Games içinde (p. 185-204). Sage Publications.

Christiansen, T. (2015). Agar.io Review: Brusting Your Buble. Erişim adresi: https://www.gamezebo.com/2015/07/14/agar-io-review-bursting-bubble/, Erişim tarihi: 14.08.2019.

Clarke, R. I., Lee, J. H. \& Clark N. (2015). Why Video Game Genres Fail: A Classificatory Analysis. Games and Culture, 12(5), 445-465. https://doi.org/10.1177/1555412015591900 
Cortese, A. (2006). Opposing Hate Speech. London: Praeger.

Council of Europe Committee of Ministers (1997). Recommendation No. R (97) 20 of The Committee of Ministers to Member States on "Hate Speech". Erişim adresi: https://rm.coe.int/CoERMPublicCommonSearchServices/DisplayDCTMContent?document $\mathrm{Id}=0900001680505 \mathrm{~d} 5 \mathrm{~b}$, Erişim tarihi: 05.09.2019.

Demirtaş-Madran, H. A. (2013). Sosyal Kimlik ve Ayrımcılık. K. Çayır ve M. A. Ceyhan (Der.). Ayrımcılık Çok Boyutlu Yaklaşımlar içinde (s. 73-85). İstanbul Bilgi Üniversitesi Yayınları.

Efsane oyunun geliştiricisi ile kısa bir söyleşi yaptık. Erişim adresi: http://agariotaktikleri.blogspot.com/p/efsane-oyunun-gelistiricisi-ile-kisa.html Erişim tarihi: 14.08.2019.

Galanxhi, H. \& Nah F. F-H. (2007). Deception in Cyberspace: A Comparison of Text-Only vs. Avatar-Supported Medium. International Journal Human-Computer Studies, 65, 770-783. https://doi.org/10.1016/j.ijhcs.2007.04.005

Gelber, K. (2002). Speaking Back: The Free Speech Versus Hate Speech Debate. Amsterdam: John Benjamins B.V.

Gentile, D. A., Lynch, P. J., Linder, J. R. \& Walsh, D. A. (2004). The Effects of Violent Video Game Habits on Adolescent Hostility, Aggressive Behaviors, and School Performance. Journal of Adolescence, 27 (1), 5-22. https://doi.org/10.1016/j.adolescence.2003.10.002

Gordon, A., S. (2015). Agar.io: Can the Play Store's Top Game Countinue to Grow?. Erişim adresi: https://corporate.miniclip.com/press_release/agar-io-can-the-play-stores-top-gamecontinue-to-grow/, Erişim tarihi: 14.08.2019.

Göregenli, M. (2013a). Temel Kavramlar: Önyargı, Kalıpyargı ve Ayrımcılık. K. Çayır ve M. A. Ceyhan (Der.). Ayrımcılık Çok Boyutlu Yaklaşımlar içinde (s. 17-40). İstanbul Bilgi Üniversitesi Yayınları.

Göregenli, M. (2013b). Nefret Söylemi ve Nefret Suçları. M. Çınar (Ed.). Medya ve Nefret Söylemi Kavramlar, Mecralar, Tartışmalar içinde (s. 57-73). Hrant Dink Vakfı Yayınları.

Grayson, N. (2015). A Game That's Become A Political Battleground. Erişim adresi: https://kotaku.com/a-game-thats-become-a-political-battleground-1707084641, Erişim tarihi: 15.08.2019.

Greitemeyer, T. (2018). The Spreading Impact of Playing Violent Video Games on Aggression. Computers in Human Behavior, 80, 216-219. https://doi.org/10.1016/j.chb.2017.11.022

Agar.io. Erişim adresi: https://en.wikipedia.org/wiki/Agar.io, Erişim tarihi: 14.08.2019.

Huizinga, J. (2003). Homo Ludens A study of The Play-Element in Culture. Routledge.

Hull, C. L. (2003). Poststructuralism, Behaviorism and The Problem of Hate Speech. Philosophy and Social Criticism, 29(5), 517-535. https://doi.org/10.1177/01914537030295002

İnceoğlu, Y. ve Çoban, S. (2014). 'Öteki’ leştirme Sürecinde Medyanın Yeri. Y. İnceoğlu ve S. Çoban (Der.). Azınlıklar, Ötekiler ve Medya içinde (s. 50-102). Ayrıntı Yayınları.

Kan, D. (2012). Yeni Medya Aracı Bilgisayar Oyunlarında Toplumsal Cinsiyetin İnşası. The Turkish Online Journal of Design-Art and Communication, 2(4), 52-60.

Kerr, A. (2006). The Business and Culture of Digital Games. Sage Publications.

Kirriemuir, J. (2006). A History of Digital Games. J. Rutter and J. Bryce (Ed.). Understanding Digital Games içinde (s. 21-35). Sage Publications. 
Klang M. (2004). Avatar: From Deity to Corporate Property A Philosophical Inquiry Into Digital Property in Online Games. Information Communication \& Society, 7(3), 389-402. https://doi.org/10.1080/1369118042000284614

Kowert, R., Domahidi, E., Festl, R. \& Quandt, T. (2014). Social Gaming, Lonely Life? The Impact of Digital Game Play on Adolescents' Social Circles. Computers in Human Behavior, 36, 385-390. https://doi.org/10.1016/j.chb.2014.04.003

Manninen, T. (2003). Interaction Forms and Communicative Actions in Multiplayer Games. Game Studies, 3(1). Erişim adresi: http://www.gamestudies.org/0301/manninen/, Erişim tarihi: 15.08.2019.

Meadows, M. S. (2008). I, Avatar: The Culture and Consequences of Having a Second Life. New Riders.

Morningstar, C. ve Farmer F.R. (1991) The Lessons of LucasFilm's Habitat. M. Benedikt (Ed.). Cyberspace: First Steps içinde (s. 273-302). MIT Press.

Mou, Y. \& Peng, W. (2009). Gender and Racial Stereotypes in Popular Video Games. R. E. Ferdig (Ed.). Handbook of Research on Effective Electronic Gaming in Education içinde (s. 922937). IGI Global.

Nowak, K. L. (2004). The Influence of Anthropomorphism and Agency on Social Judgment in Virtual Environments. Journal of Computer-Mediated Communication, 9(2), JCMC925. https://doi.org/10.1111/j.1083-6101.2004.tb00284.x

Nowak, K. L. \& Rauh, C. (2006). The Influence of the Avatar on Online Perceptions of Anthropomorphism, Androgyny, Credibility, Homophily, and Attraction. Journal of Computer-Mediated Communication, 11, 153-178. https://doi.org/10.1111/j.10836101.2006.tb00308.x

Öztekin, H. (2015). Yeni Medyada Nefret Söylemi: Ekși Sözlük Örneği. Uluslararası Sosyal Araştırmalar Dergisi, 8(38), 925-936. https://doi.org/10.17719/jisr.20153813698

Poppelaars, M., Lichtwarck-Aschoff, A., Kleinjan, M. \& Granic, I. (2018). The Impact of Explicitmental Health Messages in Video Games on Players' Motivation and Affect. Computers in Human Behavior, 83, 16-23. https://doi.org/10.1016/j.chb.2018.01.019

Salen, K. ve Zimmerman E. (2004). Rules of Play: Game Desing Fundamentals. MIT Press.

Schroeder, R. (2002). Social Interaction in Virtual Environments: Key Issues, Common Themes and a Framework for Research. R. Schroeder (Ed.). The Social Life of Avatars: Presence and Interaction in Shared Virtual Environments içinde (s. 1-18). Springer-Verlag.

Sezen, T. İ. (2011). Dijital Oyunları Anlamak: Oyun, Anlat1, Yaz1lım ve Platform Perspektiflerinden Dijital Oyunlar. G. T. Ünal ve U. Batı (Ed.). Dijital Oyunlar içinde (s. 119-148). Derin Yayınları.

Sezen, T. İ. ve Didem, S. (2011). Dijital Oyun Tarihinin Dönüm Noktaları. G. T. Ünal ve U. Batı (Ed.). Dijital Oyunlar içinde (s. 249-284). Derin Yayınları.

Tajfel, H. (1982). Social Identity and Intergroup Relations. Cambridge University Press.

Takahashi, D. (2017). The Suprising Momentum Behind io Games Like Agar io. Erişim adresi: https://venturebeat.com/2017/02/11/the-surprising-momentum-behind-io-games-like-agario/, Erişim tarihi: 14.08.2019. 
Terek Ünal, G. (2011). 1980'li Yıllarda Dijital Oyunlarda Kadın Karakterlerin Simgesel Anlatım Açısından İncelenmesi. G. T. Ünal ve U. Batı (Ed.). Dijital Oyunlar içinde (s. 65-95). Derin Yayınları.

Turkle, S. (1995). Life on The Screen: Identity in The Age of The Internet. Simon\&Schuster Paperbacks.

Uysal, D. (2017). Bilgisayar Oyunlarında Bağımlılık, Şiddet ve Kimlik Kaybının Çocuk ve Gençler Üzerindeki Etkileri: Burkhard Spinnen'in 'Nevena' Adlı Roman1. The Journal of Academic Social Science Studies, 56, 177-200. https://doi.org/10.9761/jasss7005

Valadez J. J. \& Ferguson C. J. (2012). Just a Game After All: Violent Video Game Exposure and Time Spent Playing Effects on Hostile Feelings, Depression and Visuospatial Cognition. Computers in Human Behavior, 28(2), 608-616. https://doi.org/10.1016/j.chb.2011.11.006

Van Dijk, T. A. (2000). New(s) Racism: A Discourse Analytical Approach. S. Cottle (Ed.). Ethnic Minorities and The Media içinde (s. 33-49). Open University Press.

Wallenius, M., Rimpelä, A., Punamäki, R.-L., \& Lintonen, T. (2009). Digital Game Playing Motives Among Adolescents: Relations to Parent-Child Communication, School Performance, Sleeping Habits, and Perceived Health. Journal of Applied Developmental Psychology, 30(4), 463-474. https://doi.org/10.1016/j.appdev.2008.12.021

Weber, A. (2009). Manual on Hate Speech. Council of Europe Publishing.

Yalçın Irmak, A. ve Erdoğan, S. (2016). Ergen ve Genç Erişkinlerde Dijital Oyun Bağımlılığı: Güncel Bir Bakış. Türk Psikiyatri Dergisi, 27(2), 128-37. 